\title{
The Sea Spray Chemistry and Particle Evolution Study (SeaSCAPE): Overview and Experimental Methods
}

Jon S. Sauer ${ }^{1 \dagger}$, Kathryn J. Mayer ${ }^{1 \dagger}$, Christopher Lee ${ }^{2 \dagger}$, Michael R. Alves ${ }^{1}$, Sarah Amiri ${ }^{2,3}$, Cristina Bahaveolos ${ }^{7}$,

5 Emily B. Barnes ${ }^{4}$, Daniel R. Crocker ${ }^{1}$, Julie Dinasquet ${ }^{2}$, Lauren A. Garofalo ${ }^{5}$, Chathuri P. Kaluarachchi ${ }^{6}$, Duyen Dang ${ }^{1}$, Delaney Kilgour ${ }^{7}$, Liora Mael ${ }^{1}$, Brock A. Mitts ${ }^{1}$, Daniel R. Moon ${ }^{8,9}$, Clare K. Morris ${ }^{2}$, Alexia N. Moore ${ }^{1}$, Chi-Min $\mathrm{Ni}^{7}$, Matthew A. Pendergraft ${ }^{2}$, Daniel Petras ${ }^{2,10}$, Rebecca Simpson ${ }^{2}$, Stephanie $\mathrm{Smith}^{2}$, Paul R. Tumminello ${ }^{1}$, Joseph L. Walker ${ }^{2}$, Paul J. DeMott ${ }^{11}$, Delphine K. Farmer ${ }^{5}$, Allen H. Goldstein ${ }^{4,12}$, Vicki H. Grassian $^{1,2,13}$, Jules S. Jaffe ${ }^{2}$, Francesca Malfatti ${ }^{2,14}$, Todd R. Martz ${ }^{2}$, Jonathan Slade ${ }^{1}$, Alexei V. Tivanski ${ }^{6}$,

10 Timothy H. Bertram ${ }^{7}$, Christopher D. Cappa ${ }^{8}$, Kimberly A. Prather*1,2

1. Department of Chemistry and Biochemistry, University of California, San Diego, La Jolla, California 92093, United States

2. Scripps Institution of Oceanography, University of California, San Diego, La Jolla, California 92093, United States

3. Marine Science Institute, University of California, Santa Barbara, Santa Barbara, California 93106, United States

4. Department of Civil and Environmental Engineering, University of California, Berkeley, California 94720, United States

5. Department of Chemistry, Colorado State University, Fort Collins, Colorado 80523, United States

6. Department of Chemistry, University of Iowa, Iowa City, Iowa 52242, United States

7. Department of Chemistry, University of Wisconsin, Madison, Wisconsin 53706, United States

8. Department of Civil and Environmental Engineering, University of California, Davis, California 95616, United States

9. Institute for Chemical Science, Heriot-Watt University, Edinburgh EH14 4AS, United Kingdom

10. Skaggs School of Pharmacy and Pharmaceutical Science, University of California, San Diego, La Jolla, California 92093, United States

11. Department of Atmospheric Sciences, Colorado State University, Fort Collins, Colorado 80523, United States

12. Department of Environmental Science, Policy and Management, University of California, Berkeley, California 94720, United States

30 13. Department of Nanoengineering, University of California San Diego, La Jolla, California 92093, United States

14. Universita' degli Studi di Trieste, Department of Life Sciences, Trieste, 34127, Italy

\section{Environmental Science: Processes and Impacts}

35 Correspondence to: Kimberly A. Prather (kprather@ucsd.edu)

$\uparrow$ Authors contributed equally. 


\section{Abstract}

Marine aerosols strongly influence climate through their interactions with solar radiation and clouds. However, significant questions remain regarding the influences of biological activity and seawater chemistry on the flux, chemical composition, and climaterelevant properties of marine aerosols and gases. Wave channels, a traditional tool of physical oceanography, have been adapted for large-scale ocean-atmosphere mesocosm experiments in the laboratory. These experiments enable the study of aerosols under controlled conditions which isolate the marine system from atmospheric anthropogenic and terrestrial influences.

45 Here, we present an overview of the 2019 Sea Spray Chemistry and Particle Evolution (SeaSCAPE) study, which was conducted in an 11,800 L wave channel which was modified to facilitate atmospheric measurements. The SeaSCAPE campaign sought to determine the influence of biological activity in seawater on the production of primary sea spray aerosols, volatile organic compounds (VOCs), and secondary marine aerosols. Notably, the SeaSCAPE experiment also focused on understanding how photooxidative aging processes transform the composition of marine aerosols. In addition to a broad range of aerosol, gas, and seawater measurements, we present key results which highlight the experimental capabilities during the campaign, including the phytoplankton bloom dynamics, VOC production, and the effects of photochemical aging on aerosol production, morphology, and chemical composition.

55 Additionally, we discuss the modifications made to the wave channel to improve aerosol production and reduce background contamination, as well as subsequent characterization experiments. The SeaSCAPE experiment provides unique insight into the connections between marine biology, atmospheric chemistry, and climate-relevant aerosol properties, and demonstrates how an ocean-atmosphere-interaction facility can be used to isolate and study

60 reactions in the marine atmosphere in the laboratory under more controlled conditions. 


\section{Environmental Significance Statement}

The ocean-atmosphere system influences Earth's radiative balance, cloud formation and precipitation, and air quality, all of which directly impact human health and well-being.

65 Laboratory control experiments play a key role in improving our understanding of the marine atmosphere and allow for measurements of aerosols and gases under clean, isolated, and environmentally relevant conditions. Here, we describe the design and operation of an 11,800 $\mathrm{L}$ wave channel for replicating the ocean-atmosphere environment, with specific details provided on the production of representative sea spray aerosols, marine microbiology, biogenic

70 gases, and secondary marine aerosols. The findings presented herein demonstrate best experimentation practices and illustrate challenges that exist when working to replicate and ultimately understand chemical reactions and biology feedbacks in the ocean-atmosphere system. 


\section{Introduction}

Oceans cover 71\% of Earth's surface and are a major source of both aerosols and trace gases, which affect climate, air quality, and human health. Aerosols influence climate directly by absorbing and scattering solar radiation, and indirectly by serving as cloud condensation nuclei (CCN) and ice nucleating particles (INPs), thus affecting the properties of clouds. The

80 interactions between aerosols and clouds represent one of the largest uncertainties in estimates of Earth's radiative budget (Boucher et al., 2013; Carslaw et al., 2013). Constraining the flux, composition, and cloud-relevant properties of marine aerosols is crucial for understanding their influence on atmospheric processes and establishing past and future changes in the climate system.

Sea spray aerosol (SSA) is the largest source of atmospheric particles by mass, with a global emission flux ranging from 3-30 $\mathrm{Pg} \mathrm{yr}^{-1}$ (Lewis and Schwartz, 2004), 98\% of which is attributed to supermicron particles (Gong et al., 2002). SSA is produced when breaking waves entrain air bubbles beneath the ocean surface, which rise to the surface and burst. This process produces two types of droplets: film drops from the bursting of the bubble cap and jet drops

90 from the collapse of the bubble cavity (Lewis and Schwartz, 2004; Wang et al., 2017). Spume droplets can also be formed from the direct action of wind on wave crests; however, these large droplets (up to millimeters in diameter) are rapidly removed from the atmosphere via gravitational deposition (Lewis and Schwartz, 2004). Measurements of authentic marine aerosols have been traditionally limited to studies performed on research cruises or at remote

95 field stations (O’Dowd and de Leeuw, 2007; Quinn et al., 2015). More recently, usage of oceanatmosphere simulators such as wave channels and Marine Aerosol Reference Tanks (MARTs) have enabled laboratory studies to simulate the complexity of the marine environment under controlled conditions (Prather et al., 2013; Stokes et al., 2013, 2016). These experimental systems use breaking waves or plunging waterfalls to produce bubble plumes with the correct 
100 size and surface residence time to match bubbles in the real ocean. Subsequent rupturing of these bubbles at the air-sea interface produces SSA that closely resemble the size distribution of SSA observed in the marine environment.

These ocean-atmosphere simulators have been compared with other laboratory SSA production devices such as fritted bubblers and shown to have several key advantages (Collins et al., 2014; Stokes et al., 2013, 2016). While simple in design and application, fritted bubblers tend to produce less representative aerosol size distributions, resulting in physiochemical discrepancies in morphology and composition (Collins et al., 2014). The use of oceanatmosphere simulators to generate realistic marine aerosols has led to a variety of new insights into marine aerosol chemistry and production (Mayer et al., 2020a). This includes the production of marine ice nucleating particles (INPs) (DeMott et al., 2015); the aerosolization of marine microorganisms (Michaud et al., 2018); biochemical control of SSA composition (Wang et al., 2015); biogenic volatile gas production (Kim et al., 2015); physical and chemical heterogeneity of SSA (Lee et al., 2020b; Patterson et al., 2016); and SSA surface reactivity and gas uptake (Ault et al., 2013; Ryder et al., 2015). The further use of these simulators to

115 disentangle the wide range of processes that occur in the marine environment is being advanced by improvements in their construction and understanding the factors which are relevant for ideal operation.

While many ocean-atmosphere studies have focused solely on the composition and properties of freshly emitted nascent SSA (nSSA), atmospheric aging processes can transform

120 SSA through reactions with trace gases, oxidants, and sunlight. For example, heterogenous reactions of SSA with $\mathrm{HNO}_{3}$ results in the displacement of $\mathrm{HCl}$, forming $\mathrm{NaNO}_{3}$ (Ault et al., 2013) and reaction with basic sites present within biological coatings (Estillore et al., 2016; Trueblood et al., 2016). In addition to SSA, the oceans are a source of secondary marine aerosol (SMA), which is formed from the reactions of VOCs emitted from seawater. SMA can either form as new particles via nucleation or it can condense onto existing particles in the marine 
atmosphere, such as SSA, changing their size and chemical composition (O'Dowd and de Leeuw, 2007). However, in field studies, it is extremely difficult to constrain the biological and chemical processes which lead to SMA formation and control its properties. Recently, oxidation flow reactors (OFRs) have been used to simulate both the heterogeneous oxidation

130 of SSA (Trueblood et al., 2019b) and the formation of SMA (Mayer et al., 2020b; Schneider et al., 2019) in laboratory studies of marine mesocosms.

Here we detail the features and usage of a newly constructed wave channel located at the Scripps Institution of Oceanography, focusing on performance and results from a two-month experimental campaign which focused on the production and measurement of marine aerosols.

135 The Sea Spray Chemistry and Particle Evolution (SeaSCAPE) experiment was designed to study marine chemistry, microbiology, VOCs, and aerosols across the ocean-atmosphere interface, under clean, isolated conditions. To enable this, the wave channel was modified to optimize the production and collection of SSA. In addition, an ancillary sampling device was constructed to facilitate the study of marine gases and secondary aerosol formation from the

140 seawater in the wave channel with minimal background contamination. Characterization experiments informed various modifications to wave channel construction and insights into best practices for operation, while also giving context for future analyses of data collected using this platform. We further outline the scope and scale of the SeaSCAPE experiment, including selected results that demonstrate the types of new discoveries enabled by the mesocosm

145 experiments discussed herein, with an emphasis on the incorporation of atmospheric oxidation processes.

\section{Methods and Materials}

\subsection{Description of Wave Channel}

The Scripps Institution of Oceanography (SIO) wave channel is a $33 \mathrm{~m}$ x $0.5 \mathrm{~m} \times 0.8 \mathrm{~m}(\mathrm{~L}$ 150 x W x H) channel located inside the Hydraulics Laboratory. The wave channel is constructed 
of a series of $2 \mathrm{~m}$ long glass panels supported by a steel scaffold. When filled to a depth of 0.56 $\mathrm{m}$ with seawater, it holds a total water volume of $11,800 \mathrm{~L}$ (Figure 1). Waves are generated by a paddle with a surface area of $0.96 \mathrm{~m}^{2}$, powered by an electromagnetically driven linear motor (H2W Technologies). This design has key advantages over previously used hydraulically driven motors, mainly oil-free bearings and extended operation time. The paddle was operated at $0.3 \mathrm{~Hz}$ with a stroke length of $73 \mathrm{~cm}$, which generates waves that break just beyond a submerged fiberglass ramp which functions as an artificial "beach" located midway down the channel. This beach (2.4 $\mathrm{m}$ in length) starts from the bottom of the flume channel and is positioned at an angle of approximately $16^{\circ}$ relative to the bottom of the channel and sits $\sim 5$

$160 \mathrm{~cm}$ below the quiescent water surface. Each breaking wave generates a plume of entrained bubbles with a similar size distribution and residence time as those in the ocean (Prather et al., 2013; Wang et al., 2015b). A second beach, located at the downstream end of the channel (Figure 1, Location 10), serves to dissipate residual wave energy and prevent disruption of wave breaking at the primary beach. The top of the channel is sealed from the paddle tank to a

165 distance $20.6 \mathrm{~m}$ downstream with acrylic lids, backed by marine-grade plywood for support. (Figure 1c). Adhesive backed foam strips were used to create a seal between the lids and the top of the wave channel, and then secured with vinyl-backed fabric tape. A PTFE sheet was suspended vertically from the last lid section to the water surface to reduce backflow of room air into the channel (Figure 1, Location 7). In addition, the open section at the end of the wave

170 channel was covered with lightweight polyethylene film to prevent dust and debris from settling into the channel.

Sampling ports for aerosol and gas measurements of the channel headspace were positioned at three locations throughout the wave channel (Figure 1 Locations $4,6 \mathrm{a} / \mathrm{b}$ ). The sampling ports consist of a stainless-steel bulkhead with a steel sampling tube which extend $0-10 \mathrm{~cm}$ below

175 the lids into the headspace. An upstream sampling port located before the wave break was used to monitor background particle and gas concentrations (Figure 1, Location 4). The sampling 
ports downstream from the wave break were used for measurements of SSA and VOCs (Figure 1, Locations 6a and 6b). The two sampling locations were located $1.5 \mathrm{~m}$ apart to accommodate the large number of sampling devices, which were positioned on top of the wave channel.

The paddle assembly, including motors, is enclosed within a tent made of flexible PTFE film (TEKFILM, FEP2000E, $0.127 \mathrm{~mm}$ in thickness) to seal the system and prevent contamination from the room air, while accommodating pressure fluctuations caused by the reciprocating paddle. Particle-free air was delivered to the wave channel from the top of the tent (Figure 1) using a custom air handling system made with galvanized steel duct pipes and stainless-steel connectors to the PTFE tent and the channel. Ambient air pulled in using a custom fan-blade powered by an induction motor (Marathon Electric 5THW8) was filtered through a four-stage filter system (Hydrosil International), consisting of a pre-filter, activated charcoal pellets, potassium permanganate $\left(\mathrm{KMnO}_{4}\right)$, and a HEPA filter. The scrubbed air was then directed into the wave channel headspace. The charcoal pellets served to reduce background VOC concentrations and the potassium permanganate served to remove acidic gases and other air pollutants. A condensation particle counter (CPC) positioned upstream of the wave break (Figure 1, Location 4) was used to continuously monitor background particle counts in the headspace, indicating breakthrough from the filter system as well as leaks in the paddle tent. Headspace concentrations of $\mathrm{NO}_{\mathrm{x}}, \mathrm{SO}_{2}$, and $\mathrm{O}_{3}$, as well as air velocity, temperature, and relative humidity were also semi-continuously monitored from the same upstream sampling location (see Section 2.5.1).

The wave channel was equipped with fluorescent lights to provide the light flux necessary for photosynthetic organisms to grow within the seawater. Four light fixtures, two on either side, were attached to the outside of each $2 \mathrm{~m}$ glass panel of the channel below the water surface. Each fixture was equipped with two $120 \mathrm{~cm}$ fluorescent bulbs (Spectra 5700K F32T8, Full Spectrum Solutions, Inc), giving a total of 8 bulbs per panel. The lights extended the full length of the channel, except for the paddle tank at the front of the channel and the end 
tank, which are constructed of stainless steel and thus not transparent to light. The flux of photosynthetically active radiation (PAR) in the channel was measured to be $\sim 80 \mu \mathrm{E} / \mathrm{m}^{2} \mathrm{~s}$ in the center of the channel, approximately $\sim 30 \mathrm{~cm}$ below the water surface (Apogee Instruments, MQ-200). While this is significantly lower than typical daytime PAR levels, which often exceed $1,000 \mu \mathrm{E} / \mathrm{m}^{2} \mathrm{~s}$ on clear days (Bouvet et al., 2002), it is comparable to PAR levels reported in other studies for the purpose of growing marine phytoplankton (Lee et al., 2015). To approximate day/night light cycles, the lights were operated on a timer which turned on for

21014 hours during the daytime and off for 10 hours at nighttime.

\subsection{Wave Channel Characterization Experiments}

Control experiments for characterizing the wave channel can be divided into two main types: 1) obtaining minimum background aerosol levels and 2) optimizing the sampling

215 location and depth into the channel headspace. For the control experiments, the wave channel was filled with sand-filtered coastal seawater. This seawater is continually pumped from Ellen Browning Scripps Memorial Pier (Scripps Pier, 32-52'00" N, 117-15'21" W), filtered, and circulated directly into the research buildings at SIO, including the wave channel. As sandfiltration removes most of the large biological species (>1-2 $\mu \mathrm{m})$ and results in microbiology that differs significantly from the seawater used in mesocosm experiments, this seawater was only used for wave channel characterization and testing.

\subsubsection{Background particle concentrations}

Using flexible PTFE film, a box-shaped tent of $244 \mathrm{~cm}$ length $\times 117 \mathrm{~cm}$ height x $80 \mathrm{~cm}$ depth was fabricated with double heat-sealed edges and suspended in a stainless-steel frame over the paddle (Figure 1, Location 2). The seam between the tent and the wave channel metal body was sealed using polyester tape (3M $8403,5 \mathrm{~cm}$ diameter). Total particle counts in the 
wave channel were measured before and after the wave break with condensation particle counters (Magic CPC, Aerosol Devices Inc). The purpose of the upstream CPC was to detect

230 particle leaks in the paddle tent and the air handling system. Counts were typically very low $\left(\sim 3 \# / \mathrm{cm}^{3}\right)$. The downstream CPC measured the total number of particles after the breaking wave. Thus, we assume that the difference between upstream and downstream particle counts is the total number concentration of SSA generated by the breaking wave. During most of the study, the upstream counts were negligible, thus during these periods, we assumed that all the particles measured downstream were SSA generated by wave breaking.

\subsubsection{Sampling location optimization}

Aerosol size distributions of nSSA were measured using an Aerodynamic Particle Sizer (APS 3321, TSI Inc) and a Scanning Mobility Particle Sizer (SMPS 3938, TSI Inc) equipped

240 with an X-ray neutralizer (Model 3088, TSI Inc) at various locations downwind of the wave break (5 locations, $60 \mathrm{~cm}$ intervals) at $0-10 \mathrm{~cm}$ below the channel lid. The induction motor was tuned between 1250 and 2500 rotations per minute (RPM) to vary the airflow and determine the response of the total particle number concentration. Particles were dried prior to measurement with a silica diffusion dryer. The electrical mobility diameters $\left(d_{m}\right)$ measured by the SMPS are assumed to be the same as the physical diameter $\left(d_{p}\right)$. The aerodynamic diameters $\left(d_{a}\right)$ measured by the APS were converted to physical diameter using the effective density of sea spray aerosol $\left(\rho_{\text {eff }}=1.8 \mathrm{~g} \cdot \mathrm{cm}^{-3}\right)$ (Stokes et al., 2013).

\subsubsection{Wave channel headspace velocity}

Measurements of the wave channel air velocity were obtained during paddle operation by injecting $50 \mu \mathrm{L}$ of $45 \mathrm{mM}$ dimethyl sulfide (DMS) in methanol into the wave channel headspace at the upstream sampling port. As DMS was carried along the length of the wave 
channel by the headspace flow, a home-built chemical ionization time of flight mass spectrometer (CI-ToF-MS) drew headspace at 2 slpm from the first downstream sampling port

255 (Figure 1, Location 6a). The operation of the CI-ToF-MS instrument is described in detail below (Section 2.6.2).

\subsection{SeaSCAPE Bloom Initiation}

\subsubsection{Wave Channel Cleaning Procedures}

The wave channel was cleaned and sanitized prior to all experiments and induced bloom measurements. The channel was first filled and flushed with fresh water to remove any large debris, then the inside walls were sprayed with a $3 \%$ acetic acid/water mixture. A combination of soft sponges and brushes were used to manually remove any film or debris from the inner walls. Once completed, the channel was flushed with fresh water to remove all of the cleaning solution. As a final rinse, the channel was filled with sand-filtered seawater, then drained.

\subsubsection{Water Collection}

Seawater was collected from the Scripps Pier. The water is pumped up from the end of the pier and travels through a gravity flume on the south side of the pier to the pier entrance. During the pumping process, the seawater passed through a rough aluminum screen to collect large marine detritus such as seaweed. A submersible pump (Grundfos UNILIFT AP12.40.04.A1) was placed into the gravity flume, and water was pumped through a hose into $1,135 \mathrm{~L}$ plastic tanks and transported to the wave channel by truck immediately after filling at the Scripps Pier. The seawater was further filtered to remove large particulates and zooplankton using an acidcleaned 50- $\mu \mathrm{m}$ Nitex nylon mesh (Flystuff; Cat \# 57-106) and pumped into the wave channel. During Blooms 1 and 2, the Nitex mesh was attached directly to the outlet submersible pump, which inadvertently created shear forces which damaged some of the more delicate 
microorganisms in the seawater. To improve the seawater collection procedure, a gravity filtration system was used during Bloom 3. Briefly, a stainless-steel frame was built to fit over

280 the top of the wave channel, to which a sheet of Nitex mesh with a surface area of $\sim 0.5 \mathrm{~m}^{2}$ was affixed. Seawater was poured over the frame, allowing it to gently filter through the mesh.

\subsubsection{Bloom Initiation}

Algae growth media and sodium metasilicate was added to the seawater at the beginning of each bloom cycle to promote phytoplankton growth (Guillard and Ryther, 1962). The dates and concentrations of the nutrient additions are summarized in Table 1. The growth media was added at two locations: the upstream sampling ports (Figure 1, Location 1) and after the end of the lid sections (Figure 1, Location 4). Both the growth media and silicates were dissolved into several liters of milliQ $\mathrm{H}_{2} \mathrm{O}$, then slowly added dropwise to the channel using a sterilized separatory funnel or polycarbonate carboy equipped with a spigot over the course of several hours. This slow nutrient addition allows the growth media to mix with the seawater in the channel and prevents compounds from precipitating out of solution due to the high salinity.

During the third bloom cycle, a separate phytoplankton bloom was grown in a $1,135 \mathrm{~L}$ cylindrical plastic tank outside of the hydraulics laboratory (Table 1). The purpose of this was to inoculate the wave channel with healthy phytoplankton biomass grown under natural sunlight to promote a larger bloom. Seawater was collected from Scripps Pier and filtered using $50-\mu \mathrm{m}$ Nitex mesh, then it was transferred to the 1,135 L outdoor tank, covered with wire mesh to keep out debris, and placed in partial shade. To stimulate the growth of a phytoplankton bloom, f/2 growth media and sodium metasilicate were added immediately and the seawater was bubbled gently to oxygenate. Once the outdoor tank reached the exponential growth phase as indicated by in situ fluorescence measurements (AquaFluor, Turner Designs), 1,135 L of water were drained from the wave channel, and the contents of the tank were added to the wave 
channel. Water was transferred gently using sanitized buckets to avoid damaging the phytoplankton during the transfer. Additional nutrients were added to the wave channel immediately following the outdoor tank addition to bring the total concentration of growth media and silicates up to $f / 2$ in the wave channel.

\subsection{Isolated Sampling Vessel and OFR Experiments}

\subsubsection{Description of Isolated Sampling Vessel}

Due to challenges associated with removing all trace gases from both the ambient air brought in via the air handler and off-gassing from wave channel materials, an isolated headspace was used to sample VOCs produced from seawater (see Section 2.6). The isolated sampling vessel (ISV) was constructed from a single cylindrical tube of borosilicate glass (Greatglas, Delaware U.S.A.) that was capped on both ends. The dimensions of the glass tube

315 were as follows: $400 \mathrm{~mm}$ outer diameter, $6 \mathrm{~mm}$ wall thickness, $74 \mathrm{~cm}$ long, resulting in a total volume of $87 \mathrm{~L}$ and a water volume of $44 \mathrm{~L}$, when filled halfway with seawater. An annotated schematic of the ISV can be found in Figure S1. Each end of the ISV was sealed by a PTFE disk, thickness $1.6 \mathrm{~mm}$, braced against the face of the cylinder by a $9.5 \mathrm{~mm}$ acrylic disk and backed by an aluminum frame. Six $6.4 \mathrm{~mm}$ stainless steel Swagelok bulkhead ports in the headspace partition were used for the zero air inlet and gas sampling outlets (located on opposite ends), with one $13 \mathrm{~mm}$ bulkhead to continuously pump seawater and a $25 \mathrm{~mm}$ bulkhead drain port located $13 \mathrm{~mm}$ above the center of a PTFE sealing plate opposite of the filling bulkhead.

Seawater was delivered to the ISV via a plunging stream located opposite the sampling ports. The seawater was circulated using a peristaltic pump equipped with Tygon tubing, which withdrew water from the wave channel, $\sim 0.5 \mathrm{~m}$ beneath the water surface. In order to maintain a consistent flow rates and prevent leaks, the tubing within the peristaltic pump was replaced 
every 3 days. ISV water drained back into the channel through $25 \mathrm{~mm}$ tubing attached to the large central port opposite the plunging jet, with the end of the return flow tubing submerged beneath the water level. Zero air flow rate through ISV headspace varied from 8-10 standard liters per minute (slpm), leading to an average air residence time of 5 minutes. The water flow rate was fixed at $1.5 \mathrm{slpm}$, leading to a water residence time of 29 minutes. The ISV was lit by two fluorescent light fixtures, which extended the length of the vessel on either side.

\subsubsection{OFR Operation}

To study the effect of atmospheric aging processes on marine aerosols, potential aerosol mass oxidation flow reactors (PAM-OFR, Aerodyne Inc) were used to simulate both the heterogeneous oxidation of primary sea spray aerosol and the formation of secondary marine aerosol from the oxidation of VOCs. The PAM-OFR uses UV lamps to produce high concentrations of $\mathrm{OH}$ radical, simulating atmospheric aging from a fraction of a day to weeks, with a residence time of 1-3 minutes (Kang et al., 2007; Lambe et al., 2011). Two OFRs (OFR1 and OFR2) sampled from the wave channel headspace (Figure 1, Location 6a), with the goal of producing heterogeneously aged SSA (hetSSA), although SMA is also produced from the oxidation of VOCs present in the wave channel headspace. Figure S2 shows a schematic of the different OFR sampling lines utilized during SeaSCAPE. Briefly, OFR1 was utilized for continuous, online measurements of hetSSA chemical composition, size distributions, and hygroscopicity. In contrast, OFR2 was utilized for a combination of online and offline measurements including aerosol chemical composition, phase and morphology, and INP characteristics. A third OFR (OFR3) sampled from the ISV (Figure 1), for the purpose of producing SMA under clean conditions. A full inventory of aerosol measurements conducted using the OFRs can be found in Tables 2 and 3. 
All OFRs were operated in OFR185 mode, meaning the UV lamps produce light with wavelengths of both $185 \mathrm{~nm}$ and $254 \mathrm{~nm}$. The $\mathrm{OH}$ exposure at each lamp intensity was determined by introducing carbon monoxide to the OFR and measuring the drop in $\mathrm{CO}$ concentration due to oxidation using a $\mathrm{CO}$ analyzer (APMA-370, Horiba Ltd). The $\mathrm{OH}$ exposure is determined using the rate coefficient of $\mathrm{CO}+\mathrm{OH}\left(k_{\mathrm{OH}}+\mathrm{CO}, 298 \mathrm{~K}=1.5 \times 10^{-13} \mathrm{~cm}^{3}\right.$ molec $^{-1} \mathrm{~s}^{-1}$ ), assuming pseudo-first order kinetics (Chen and Marcus, 2006). The $\mathrm{OH}$ exposure can be converted to "days of equivalent aging" using typical tropospheric $\mathrm{OH}$ concentrations $\left([\mathrm{OH}]=1.0 \times 10^{6} \mathrm{molec} \cdot \mathrm{cm}^{-3}\right)$ (Wolfe et al., 2019). $\mathrm{O}_{3}$ concentrations were monitored downstream of each of the OFRs using an $\mathrm{O}_{3}$ analyzer (Model 202 and Model 106-L, 2B Technologies). Before aerosol measurements, the sample air was passed through a denuder to remove $\mathrm{O}_{3}$ (Carulite-200, obtained from Ozone Solutions).

\subsection{SeaSCAPE - Aerosol Measurements}

A large suite of aerosol measurements was conducted during the SeaSCAPE experiment to study the properties of nSSA, hetSSA, and SMA. These include measurements of the size distributions, chemical composition, INP characteristics, $\mathrm{CCN}$ activity and water uptake, and phase state and morphology, among other properties. All measurements conducted during the campaign are summarized in Tables 2 and 3.

\subsubsection{Aerosol Number and Size Distributions}

Total particle counts in the wave channel were measured before and after the wave break with condensation particle counters. The aerosol size distributions of nSSA after the wave break was measured using the APS and SMPS as described in the control experiment. Size distributions from OFR1 and OFR2, which includes both hetSSA and SMA, were measured using a Scanning Electrical Mobility Spectrometer (SEMS, Brechtel Manufacturing, Inc) and 
an APS (3321, TSI Inc). SMA size distributions from OFR3 were measured using an SMPS (Model 3938, TSI Inc) equipped with a Nano DMA (DMA 3085, TSI Inc) and a soft X-ray Neutralizer (Model 3088, TSI Inc).

\subsubsection{Single Particle Atomic Force Microscopy (AFM) Measurements}

Nascent and heterogeneously aged sea spray aerosols were collected for AFM measurements of aerosol phase and morphology throughout SeaSCAPE. A selected analysis was conducted of particles collected on $8 / 3 / 19$, which corresponded to the peak of the phytoplankton growth during Bloom 3. The nSSA were deposited onto hydrophobically treated silicon substrates (Ted Pella, Inc.) using a micro-orifice uniform deposit impactor (MOUDI, MSP, Inc., model 110) at ca. 80\% RH (i.e. wet deposition) (Lee et al., 2019). The hetSSA were deposited onto the hydrophobically treated silicon substrates using a separate MOUDI (MSP, Inc., model 125R) at ca. 20\% RH (i.e. dry deposition) (Lee et al., 2019, 2020a). MOUDI stages 6, 7 and 8 were used, which corresponds to an aerosol aerodynamic diameter $50 \%$ cut off range of $0.18-1.0 \mu \mathrm{m}$. The hetSSA were generated using OFR2, with a UV lamp voltage of $2.0 \mathrm{~V}$ which corresponds to approximately 4-5 days of photochemical aging in the atmosphere. The substrate-deposited nascent and hetSSA samples were stored in clean Petri dishes and kept inside a laminar flow hood (NuAire, Inc., NU-425-400) at ambient temperature $\left(20-25^{\circ} \mathrm{C}\right)$ and pressure.

AFM height images of individual nascent and hetSSA particles were recorded using the molecular force probe 3D AFM (Asylum Research, Santa Barbara, CA), at ambient temperature $\left(20-25^{\circ} \mathrm{C}\right)$ and pressure. Silicon nitride AFM tips (MikroMasch, Model NSC35, tip radius of curvature $\sim 10 \mathrm{~nm}$ ) were used to image individual particles. A custom-made

400 humidity cell was used to control the RH at 50\% for all imaging; the elevated RH was used due to expected lowering of the viscosity for the organic components relative to inorganic that 
facilitates differentiation of their spatial distribution using AFM (Lee et al., 2019). AC mode AFM was used to image individual particles and determine their morphology. A total of 50 individual particles were characterized for each sample type.

\subsubsection{Aerosol Mass Spectrometry (AMS)}

The chemical composition of submicron non-refractory aerosol was determined by high resolution time-of-flight aerosol mass spectrometry (HR-TOF-AMS; Aerodyne, Inc.) (DeCarlo et al., 2006). The AMS was operated in V-mode with standard MS mode (5s open, 5s closed) and PTOF (10s) with typically 5-min sampling averages.

\subsection{SeaSCAPE - Gas-phase Measurements}

In addition to the gas-phase measurements discussed below, Table 4 details the full inventory of gas-phase measurements conducted during SeaSCAPE to assess questions

415 regarding VOCs produced from seawater and anthropogenic contaminants.

\subsubsection{Trace Inorganic Gases}

The concentrations of trace gases were monitored at several locations: the air handling system, room air, and the wave channel headspace, upstream of the wave break. A customfabricated solenoid valve switching array was used to automatically switch between the

420 different air sampling lines. The concentrations of the oxides of nitrogen (NOx) were continuously monitored using a Model 42C NO-NO2-NOx analyzer (Thermo Electron Corporation). Ozone concentrations were measured using a UV photometric based $\mathrm{O}_{3}$ analyzer (Model 49C, Thermo Electron Corporation). The analyzer was calibrated using an ozone calibration source (Model 306, 2B Technologies). Sulfur dioxide concentrations were

425 measured using a pulsed fluorescence $\mathrm{SO}_{2}$ analyzer (Model 43iQ Trace Level $\mathrm{SO}_{2}$ Analyzer, Thermo Electron Corporation). 


\subsubsection{Chemical Ionization Time of Flight Mass Spectrometry}

A home-built CI-ToF-MS, modeled on systems previously described by others, (Kercher

430 et al., 2009) was utilized to determine the headspace flow rate of the wave channel. Briefly, $\sim 300 \mathrm{ppm}$ benzene vapor was generated by passing 10 standard cubic centimeters per second $(\mathrm{sccm})$ of $\mathrm{N}_{2}$ over a cylinder of liquid benzene and diluted to concentration with added $\mathrm{N}_{2}$ (Kim et al., 2016; Lavi et al., 2017). Benzene vapor was passed through a 20mCi Po-210 $\alpha$-source to generate benzene cluster cation reagent ions, and further drawn through an inline critical orifice at $1.8 \mathrm{slpm}$ into the ion-molecule region (IMR) of the CI-ToF-MS. Sample analyte was similarly drawn into the IMR at the same flow rate as analyte. The IMR pressure was maintained at 60 Torr and $60 \mathrm{~V}$ for all analyses. Analyte ions generated through charge transfer and ligand switching reactions with benzene cluster cations were focused by a radio frequency ion funnel, and subsequently transferred by an RF-only quadrupole into an orthogonalextraction time of flight analyzer (Tofwerk). Co-summed mass spectra from $5-500 \mathrm{~m} / \mathrm{z}$ were obtained at $1 \mathrm{~Hz}$, with generated data analyzed using the Tofware plugin for Igor Pro 7 software.

\subsubsection{Proton Transfer Reaction Mass Spectrometry}

A Vocus proton transfer reaction time-of-flight mass spectrometer (PTR-ToF-MS) (TOFWERK, Aerodyne Inc.) measured headspace gas-phase VOCs (Krechmer et al., 2018). The focusing ion-molecule reactor was operated at high reduced field strength $(\mathrm{E} / \mathrm{N}=143 \mathrm{Td})$. It was held at a pressure of $1.5 \mathrm{mbar}$, electric field of $41.5 \mathrm{~V} \mathrm{~cm}^{-1}$, and temperature of $100{ }^{\circ} \mathrm{C}$. The big segmented quadrupole voltage was $275 \mathrm{~V}$, reducing the transmission of low mass $(<35$ $\mathrm{m} / \mathrm{Q}$ ) ions. The PTR-ToF-MS mass spectra were saved at $1 \mathrm{~Hz}$ time resolution. The headspace of the ISV was sampled at $100 \mathrm{sccm}$ through a roughly $2.5 \mathrm{~m}, 6.35 \mathrm{~mm}$ O.D. PFA tube. The 
air handling system and wave channel headspace were pulled down a $9.525 \mathrm{~mm}$ O.D. PFA tube approximately $\sim 15 \mathrm{~m}$ at a flow rate of $8 \mathrm{slpm}$. The PTR-ToF-MS subsampled $100 \mathrm{sccm}$ of this flow. Room air was sampled intermittently approximately 8 times throughout the day. Instrument background signals were determined about 8 times daily by overflowing the PTRToF-MS inlet with zero air from the zero-air generator (Sabio 1001) that provided air to the ISV headspace. Daily average background signals were used for background correction. Peak fitting and integration were completed in Tofware 3.1.2.

\subsubsection{Offline Atmospheric Pressure Chemical Ionization for Irradiation}

\section{Experiments}

A high-resolution Orbitrap Elite (ThermoFisher) mass spectrometer equipped with a modified gas-phase atmospheric pressure chemical ionization (APCI) source was used to detect VOCs that evolved from the surface of water collected during the SeaSCAPE campaign upon irradiation using an LCS-100 solar simulator (94011A, Oriel), adapted by the approach of (Roveretto et al., 2019) . Data were collected solely in positive mode, where needle voltage was set to $4 \mathrm{kV}$, needle current at $5 \mathrm{~mA}$, and vaporizer temperature at $150{ }^{\circ} \mathrm{C}$. Sheath and auxiliary flow were set to zero. An air mass optical filter (AM 1.5G, Newport Inc.) and a water filter were used to simulate the solar spectrum and block infrared radiation, respectively. From the wave channel, $200 \mathrm{~mL}$ of surface water was collected and transferred into a $350 \mathrm{~mL}$ jacketed custom glass tube (Ace Glass Inc.) with a quartz window on each end. The surface area of the water sample in the tube was approximately $77 \mathrm{~cm}^{2}$. With a headspace of $150 \mathrm{~mL}$, pure nitrogen gas was used as a carrier at a rate of $200 \mathrm{sccm}$. Temperature was regulated and measured constantly to ensure minimal thermal variation $\left( \pm 1^{\circ} \mathrm{C}\right)$ during the experiment. The collected water settled for 2 hours before being irradiated to allow a stable surface layer to form. To verify whether the immediate spike in signal was abiotic or biotic in nature when 
under lighted conditions, a separate experiment using the same water, but filtered with a 0.2 $\mu \mathrm{m}$ GTTP filter (MilliporeSigma) to remove most biological material.

\subsubsection{Thermal Desorption Two-Dimensional Gas Chromatography}

VOCs from the ISV and from the offline irradiation experiments were collected on triple bed sorbent tubes (Tenax TA, Carbograph 1, Carboxen 1003, CAMSCO). Samples were collected at $100 \mathrm{sccm}$ for 20 minutes from the ISV headspace and $200 \mathrm{sccm}$ for 10 minutes from the offline irradiation experimental setup. Samples were frozen immediately after collection and were analyzed offline by Thermal Desorption (Gerstel TD 3.5) two-dimensional Gas Chromatography (Agilent 7980 A), modulated by two stage thermal modulation (Zoex), coupled with variable energy Electron Ionization Time of Flight Mass Spectrometry (Markes BenchToF) (TD-GCxGC-EI-ToF-MS). Data was collected at $50 \mathrm{~Hz}$, and ionization energies oscillated rapidly between $70 \mathrm{eV}$ and $14 \mathrm{eV}$ to simultaneously generate hard and soft chromatograms for each sample. Column materials and thermal methods are as described in Hatch et al. 2019.

\subsection{SeaSCAPE - Water Measurements}

Seawater measurements sought to characterize both the biotic and abiotic drivers of marine particles and gases, including nutrient availability, organic chemical composition, biological speciation, biological productivity, dissolved gas turnover and other important factors. Table 5 lists the seawater and sea surface microlayer (SSML) measurements made through the duration of SeaSCAPE. 


\subsubsection{Bulk Seawater Sampling}

Bulk seawater was sampled daily for the following analyses: dissolved organic carbon (DOC); inorganic nutrients; extracted chl-a; bacterial and viral abundances; phytoplankton identification; enzyme measurements; $16 \mathrm{~S}$ and 18S rDNA amplicon sequencing; and tandem mass spectrometry (MS/MS) based metabolomics. Seawater was collected using a $\sim 2 \mathrm{~m}$ long siphon constructed from Teflon tubing. Nalgene carboys were used to transport and dispense the collected seawater for analysis. Both the siphon and the carboys were rinsed with methanol, $70 \%$ ethanol, $0.1 \mathrm{M} \mathrm{HCl}$ solution, and ultra-purified water prior to water collection. The siphon was inserted near the end of the channel before the second beach (Figure 1) approximately 20 $\mathrm{cm}$ below the surface of the water. Approximately $16 \mathrm{~L}$ of bulk seawater were collected daily around 09:30 PST. The volume of collected seawater was replenished by adding a corresponding volume of Milli-Q (Millipore) water $(<18 \mu \Omega$ ) every other day to maintain the water level in the flume without introducing any microbiological contaminants.

\subsubsection{Sea Surface Microlayer Sampling}

Sea surface microlayer (SSML) sample collection was conducted using a glass plate, a glass funnel and a Teflon scraper. During the day preceding collection of SSML samples, the glass plate and funnel were cleaned of biological material using Millipore water, methanol, 70\% ethanol, and $10 \% \mathrm{HCl}$. The collection glassware was placed in a combustion furnace for 5 hours at $500{ }^{\circ} \mathrm{C}$ to remove organic contaminants. The glass plate with a handle was lowered carefully into the wave channel at a rate of $5-6 \mathrm{~cm} \mathrm{~s}^{-1}$ and withdrawn at the same rate. This withdrawal rate corresponds to an estimated sampled SSML thickness of around $50 \mu \mathrm{m}$ (Carlson, 1982; Cunliffe and Wurl, 2015). After removal from the wave channel, the glass plate was suspended for 20 seconds to allow any bulk seawater to drain off the plate and back into 
was scraped from the glass plate into a collection vessel using a Teflon scraper. This process was repeated until approximately $200 \mathrm{~mL}$ of sample was collected.

\subsubsection{DOM Extraction and Compositional Analysis}

Dissolved organic matter (DOM) was extracted from water samples collected from the wave channel using the solid phase extraction method described and characterized by Dittmar and coworkers (Dittmar 2008). At the end of Bloom 3, a large volume of about 2,000 L was extracted over the course of 72 hours using this method. A total of $1.51 \pm 0.01 \mathrm{~g}$ of marine DOM was collected and stored at $-18^{\circ} \mathrm{C}$ for future analyses.

Samples of extracted DOM were analyzed by TD-GCxGC-EI-HR-ToF-MS. DOM samples were reconstituted in methanol immediately prior to analysis and injected onto quartz fiber filter segments, then doped with a custom blend of 23 deuterated internal standard compounds prior to analysis, allowing corrections for instrument condition and matrix effects across samples. Briefly, the instrument thermally desorbs samples from the filter media, then

540 introduces them into the $\mathrm{GC}$ oven. The instrument employs online derivatization during thermal desorption with MSTFA (n-methyl-n-trimethylsilyl-trifluoro-acetamide). Analytes are separated by volatility and then by polarity by two GC columns in sequence. Separated analytes from are ionized by $70 \mathrm{eV}$ electron ionization (EI) and detected by HR-ToF-MS (Tofwerk). Methodological details follow Worton et al. 2017. Six-point calibration curves of custom

545 standard blends containing $~ 150$ representative organic compounds were performed periodically throughout sample analysis for each sample medium class to maximize quantification accuracy. 


\subsubsection{Chlorophyll-a, Dissolved Oxygen, and DOC Measurements}

A continuous time series of in vivo chl-a and dissolved oxygen was measured throughout all three wave channel experiments using an Environmental Sample Processor (ESP). The ESP was located at the back of the wave channel just behind the seawater sampling section (Figure 1). The ESP is a homemade, continuous flow system that pumps seawater through tubing at a flow rate around $1 \mathrm{lpm}$ using a peristaltic pump. The seawater first passed an SBE 37 MicroCAT that measures conductivity, followed by an SBE 63 optical dissolved oxygen sensor before being deposited into a reservoir. In the reservoir, chl-a is quantified through fluorescence measurements using a Sea Bird Scientific ECO-Triplet-BBFL2 sensor at excitation/emission wavelengths of $470 / 695 \mathrm{~nm}$. After measurement of chl-a, the seawater is circulated out of the ESP and back into the wave channel.

Each morning, the ESP was rinsed by circulating Millipore water through the tubing for 20 minutes, and every fourth day, solutions of $0.1 \%$ bleach, $30 \%$ ethanol, and Millipore water were sequentially circulated through the tubing for 20 minutes to thoroughly clean the instrument. This helped prevent biological growth in the tubing and biofouling of the optics. Additionally, in between each experiment, the reservoir was removed from the laser optics and both were carefully wiped with $70 \% \mathrm{EtOH}$. Any ESP measurement periods that were affected by instrument maintenance or biofouling were corrected using in vivo chl-a measurements made by a hand-held fluorometer (AquaFluor, Turner Designs). AquaFluor chl-a measurements were made every few hours from the seawater sampling section of the wave channel.

To calibrate both the ESP and AquaFluor chl-a measurements, chl-a was extracted from the bulk seawater and analyzed by fluorometric analysis in accordance with CALCOFI methods (Holm-Hansen et al., 1965). The seawater was collected once daily from the wave channel (as described in Section 2.7.1) and filtered on $25 \mathrm{~mm}$ Whatman GF/F filters. The filters 
were then submerged in $8 \mathrm{~mL}$ of $90 \%$ acetone for 24 hours at $-20{ }^{\circ} \mathrm{C}$ to extract the chl-a.

Concentrations of the extracted chl-a were determined by a calibrated fluorometer (10AU, Turner Designs). The extracted chl-a measurements were separately plotted against both the ESP and AquaFluor data, and each plot was fitted with a least squares regression used to calibrate the ESP and AquaFluor chl-a values. A continuous time series of the calibrated ESP chl-a data for all three experiments is shown in Figure 2.

For DOC measurements, two $40 \mathrm{~mL}$ aliquots of the bulk seawater (see Section 2.7.1 for details of water collection) were filtered into combusted glass vials through a Whatman GF/F filter with a $0.7 \mu \mathrm{m}$ pore size. Functionally this implies that the DOC was comprised of OC with diameters $<0.7 \mu \mathrm{m}$. The vacuum filtration was carried out using a hand pump to minimize cell lysis during filtration. The DOC samples were immediately acidified to $\mathrm{pH} \sim 2$ with three drops of concentrated $\mathrm{HCl}$ and stored in a covered box at room temperature until analysis. All DOC concentration measurements were made on a Shimadzu TOC-V $V_{C S H}$ catalytic combustion oxidation instrument.

\subsubsection{Phytoplankton Enumeration and Photography}

In order to determine the taxonomic composition of the mesocosm, two methods were employed: 1) Whole seawater samples were collected and manually counted under confocal microscopy; 2) A dual version of the Scripps Plankton Camera System (SPCS: https://spc.ucsd.edu) was placed on the bottom of the wave channel to continuously image the developing plankton community for in situ observations. The SPCS was positioned at the downstream end of the channel, just in front of the dampening beach (Figure 1). For the manual counting method, $400 \mathrm{~mL}$ of seawater was collected from approximately $30 \mathrm{~cm}$ depth at both ends of the wave channel. Samples were taken twice per day with Teflon tubing and poured gently into amber Nalgene bottles. Samples were immediately fixed with a $2 \%$ buffered 
formalin solution and stored at $6{ }^{\circ} \mathbf{C}$ to preserve samples for enumeration. From these, $50 \mathrm{~mL}$

subsamples were then poured into a settlement chamber and allowed to settle for $24 \mathrm{hrs}$. The cells were prepared for enumeration using the Utermöhl method under an Olympus IX-71 inverted microscope (Utermöhl, 1931). Samples from the settlement chamber were counted to calculate the cell concentrations per L for each distinct species. Then, the taxa cell counts were binned into functional phytoplankton types, including a microzooplankton group. These bins were used to calculate the relative abundance of the functional groups over time and were then compared to the in-situ camera data.

The in-situ camera enabled the research team to study the plankton community undisturbed in the mesocosm, monitor the presence of delicate taxa, and observe intra- and inter-species interactions. The goal of the image analysis was to target detritus, aggregates, phytoplankton and zooplankton between $20-1000 \mu \mathrm{m}$ in major axis length. For this reason, only images collected by the 5x magnification system of the SPCS were considered. Over the course of the 3-week experiment, nearly $1.85 \times 10^{6}$ images of particles were collected within this size range. The system uses darkfield illumination to image free-floating particles in approximately 3 $\mu \mathrm{L} /$ frame sampling volume with a resolution of 3-5 $\mu \mathrm{m}$ (Orenstein et al., 2020). In order to

train a neural net to classify this large amount of data, a subset of the images was manually labelled to serve as a training set.

\subsubsection{Bacteria, virus, nano-and picophytoplankton, and heterotrophic nanoflagellates enumeration}

Bacteria, cyanobacteria and viruses in the seawater, SSML and nSSA were enumerated with a BD FACSCanto II $^{\mathrm{TM}}$ flow cytometer (FCM, bacteria, cyanobacteria and viruses). Samples were prepared according to established protocols (Brussaard, 2004; Gasol and Del Giorgio, 2000; Marie et al., 1997). All samples were preserved with glutaraldehyde at 5\% final 
concentration and stored at $-80^{\circ}$ (Noble and Fuhrman, 1998). For heterotrophic bacteria

staining, the samples were diluted with Tris-EDTA buffer $(\mathrm{pH} 8)$, then stained with SYBR Green (Gasol and Del Giorgio, 2000). For virus staining, water was diluted (1:50) in 1×TE buffer (pH 8) and stained with SYBR Green (Brussaard, 2004). Aliquots of seawater and SSML samples were analyzed unstained for counting Cyanobacteria (Olson et al., 1990). SSA samples were collected into $0.7 \mathrm{~mL}$ 4X PGE (prepared as 4x PBS, 20\% glycerol, $20 \mathrm{mM}$ EDTA) buffer using a Liquid Spot Sampler (SS110A, Aerosol Devices Inc), which sampled at $1.8 \mathrm{lpm}$ (Hering et al., 2014). The liquid sample was brought to $1 \mathrm{~mL}$ by adding 4XPGE, then split into two $0.5 \mathrm{~mL}$ aliquots that were processed as described above for FCM counting of heterotrophic bacteria and viruses. SSA blank samples were also collected via Spot Sampler with a HEPA filter on the inlet and processed accordingly. The values counted in the same SSA blank gates were subtracted from the SSA sample runs. For heterotrophic bacteria and viruses, the samples were analyzed at medium rate $\left(60 \mu \mathrm{L} \mathrm{min}{ }^{-1}\right)$ with a threshold set on green fluorescence. Side scatter versus green fluorescence plots were generated to identify and quantify heterotrophic bacteria and viral populations (Marie et al., 1997; Olson et al., 1990). Synechococcus population were identified on forward scatter versus orange fluorescence and red fluorescence. Samples for nano, picophytoplankton and heterotrophic nanoflagellates were run on a BD Accuri FCM following established protocols (Christaki et al., 2011a; Marie et al., 2014).

\section{Results: Characterization and Optimization of the Wave Channel}

\subsection{Contaminant contributions to wave channel headspace composition}

Volatile organic compounds were measured in the wave channel headspace, air handling system, ISV, and room air, with PTR-ToF-MS to determine whether they originate from a marine biogenic source or anthropogenic contamination (Figure 3). Dimethyl sulfide 
(DMS) and methanethiol (MeSH) were chosen as proxies for expected marine biogenic VOCs

650 in comparison to benzene and toluene which are more closely associated with anthropogenic pollutants and are not expected to be produced biogenically in large quantities in the marine environment (Wakeham et al., 1986). Figure 3 shows that benzene and toluene were most elevated in room air, the air handling system, and the wave channel headspace, but were significantly diminished in the ISV. These results suggest that the primary source of benzene

655 and toluene in the wave channel was not derived from the seawater, but likely as breakthrough of the air handling system. Conversely, the concentrations of DMS and MeSH in the ISV were significantly elevated compared to the wave channel, due to the lower air flow rate and higher relative water surface area. These results show that the ISV was effective in maintaining a clean headspace that better reflects the emissions of gases present in seawater with minimal 660 anthropogenic background.

\subsection{Wave channel headspace velocity}

Given the unique aspects of the wave channel, which features a highly longitudinal construction, with air introduction at one side, and a propagating water wave inside, a short

665 investigation undertaken to determine the headspace flow velocity along the channel length at a fan speed of 1500 RPM using spikes of injected DMS at the upstream port. Shown in Figure 4 is the arrival of DMS spikes at the downstream sampling port (Figure 1, Location 6a) measured by CI-ToF-MS. Mean arrival time was $200 \pm 35$ seconds $(\mathrm{N}=3)$ with the paddle running. Replicate experiments with the paddle stationary did not yield arrival times that

670 significantly differed. Given the distance of the upstream sampling port from the downstream ports, the wave channel headspace velocity was calculated to be $4.9-7.0 \mathrm{~cm} / \mathrm{second}$. 


\subsection{Characterization of particle backgrounds and SSA production}

Background particle concentrations were measured in the wave channel headspace at the upstream sampling port (Figure 1, Location 1) using a CPC to determine the contribution of non-marine particles from sources such as leaks in the paddle tent or breakthrough in the air handling system while the waves were being generated. Setting the RPM of the induction motor that supplied clean air to the wave channel to a speed less than 1500 RPM introduced ambient non-marine particles into the wave channel headspace (10-50x more), thus establishing a lower limit of the air handling unit. While increasing the speed of the motor could increase the amount of clean air into the headspace of the wave channel, doing so dilutes the total number of SSA from wave breaking, thus our testing found that 1500 RPM was the optimal setting (Figure 5a).

With the optimized setting of the air handling unit, these background particle concentrations were generally low $\left(\sim 3 \# / \mathrm{cm}^{3}\right.$, Figure 8$)$, indicating that the wave channel headspace was quite clean, with respect to ambient particulate contamination $\left(\sim 10,000 \mathrm{\#} / \mathrm{cm}^{3}\right)$. In comparison, the average particle concentrations after the breaking wave were significantly higher $\left(242 \pm 91 \mathrm{\#} / \mathrm{cm}^{3}\right)$, indicating that the vast majority (>98\%) of the particles sampled downwind of the breaking wave were sea spray aerosols produced in the wave channel.

With the air handling unit and the background optimized, the next step was to optimize the sampling location for SSA downwind of the breaking waves. Five locations at $0 \mathrm{~cm}, 60 \mathrm{~cm}$, $120 \mathrm{~cm}, 180 \mathrm{~cm}$, and $240 \mathrm{~cm}$ downwind of the breaking wave were tested. The APS and SMPS size distributions were used to calculate the total SSA number at each location. Figure $5 \mathrm{~b}$ shows that position 4, which corresponds to $180 \mathrm{~cm}$ downwind of the breaking waves, had the highest SSA number concentrations. The continuous water and air flows pushed the entrained air bubbles and the generated SSA downwind of the breaking wave (Lewis and Schwartz, 2004; Prather et al., 2013). In addition to sampling location, the sampling port $(1.27 \mathrm{~cm}$ i.d.) depth was tested, from $0 \mathrm{~cm}$ to $10 \mathrm{~cm}$ into the headspace as measured from the lid panel. While the 
specific relationship between port depth and SSA number concentration varied with sampling location, at position 4 , a port depth of $5 \mathrm{~cm}$ yielded the highest values. However, lack of clear trend in the total number concentration as a function of sampling location and depth indicates that there may be heterogeneous mixing within the wave channel headspace due to flow turbulence. In addition, factors such as wall losses and gravitational deposition of particles may have influenced the variability in particle numbers. It was observed during testing that sampling port depths of $10 \mathrm{~cm}$ or greater were prone to splashing by the breaking waves, resulting in water being pulled into the sampling lines. Similarly, a port depth of $0 \mathrm{~cm}$ (flush with the lid surface) resulted in condensation from the lids being pulled into the sampling lines. Thus, from an operational standpoint, a sampling port depth of $2-8 \mathrm{~cm}$ is ideal to minimize the introduction of water to the sampling lines.

710 4. Results from the SeaSCAPE Experiment

\subsection{Biological dynamics of phytoplankton blooms}

The time series of seawater chl-a, heterotrophic bacteria, and dissolved organic carbon, shown in Figure 4a, provide an overview of the biological progression of Bloom 3. No significant phytoplankton growth was observed after the first nutrient addition (chl-a $<2 \mu \mathrm{g} / \mathrm{L}$,

715 Figure 4a), possibly due to light limitation. A phytoplankton bloom was induced in an outdoor tank with natural seawater collected as before and then added to the wave channel on 8/1 (Table 1). After the addition of the outdoor-grown bloom, the phytoplankton growth continued and peaked at $25 \mu \mathrm{g} / \mathrm{L}$ chl-a, and then proceeded through an extended senescent phase (Figure $4 \mathrm{a}$ ). Following the peak of the bloom, chl-a concentrations remained stable around $5 \mu \mathrm{g} / \mathrm{L}$, higher than the pre-bloom state, suggesting some phytoplankton growth was still occurring. Bacterial and viral dynamics (Figure4a) followed a typical microbial succession generally observed during phytoplankton bloom (Buchan et al., 2014). 
The combination of in-situ camera and inverted microscopy, along with chlorophyll concentrations over time, confirmed a distinct natural bloom progression in Bloom 3 (Figure6).

725 Phytoplankton community structure was initially dominated by diatoms (composed mostly of Skeletonema sp. and Cylindrotheca sp.) with an overall relative abundance of $55 \%$ and $1.9 \times$ $10^{6} \mathrm{cells} / \mathrm{L}$. The community then shifted towards an aggregation of diatoms (composed mostly of Cylindrotheca sp. and Navicula sp.) at the end of the bloom with a relative abundance of $33 \%$ and $5.0 \times 10^{5}$ cells/L. There was also a proliferation in microzooplankton (composed

730 mostly of tintinnids and copepods) at the end of the bloom with a relative abundance of $25 \%$ and $5.452 \times 10^{3}$ cells/L. Phytoplankton physiology across the bloom was screened with both methods, and showed signs of pigment loss, broken frustules, and increased aggregation over time.

\section{4.2 Temperature, relative humidity, dissolved gases, and DOC}

Over the course of Bloom 3, dissolved organic carbon steadily increased in concentration, due to both primary production and bacterial production of DOC, which is consistent with previous bloom incubation experiments (Wang et al., 2015) Notably, the addition of the outdoor tank resulted in a DOC increase of $100 \mu \mathrm{M}$ compared to the background level of the

740 first week. The dissolved inorganic gases, $\mathrm{O}_{2}$ and $\mathrm{CO}_{2}$, varied on a diurnal basis as the phytoplankton utilized light for photosynthesis and produced $\mathrm{O}_{2}$ as a byproduct during the daytime. During periods of higher chl-a (Figure 2a), after the outdoor tank amendment, dissolved $\mathrm{O}_{2}$ concentrations were generally more elevated, except for $8 / 2$ when the heterotrophic bacteria reached a local maximum concentration. The dissolved $\mathrm{CO}_{2}$ concentration steadily decreased with respect to chl-a due to increased carbon fixation by phytoplankton. After reaching a minimum on $8 / 5$ (Figure $4 \mathrm{~b}$ ), the $\mathrm{CO}_{2}$ concentration began 
increasing during the senescent phase of the mesocosm probably in response to increased bacterial respiration relative to carbon fixation by phytoplankton.

The seawater temperature of the wave channel initially began at the temperature of the ocean $\left(17^{\circ} \mathrm{C}\right)$ but equilibrated quickly to the temperature of the hydraulics laboratory within $\sim 24$ hours (Figure $4 \mathrm{~b}$ ). Daily, temperature varied $\sim 0.75^{\circ} \mathrm{C}_{\text {day }}{ }^{-1}$ with the ambient temperature of the laboratory. Longer term variation in water temperature followed changes in local weather but ranged between $24.5-27^{\circ} \mathrm{C}$ for the duration of experiment after initial equilibration. The air temperature and relative humidity in the wave channel headspace also exhibited a strong diurnal cycle (Figure S3). The mean air temperature during the campaign was $24 \pm 1^{\circ} \mathrm{C}$ and the relative humidity was $86 \pm 5 \%$. Keeping both the seawater and headspace air at controlled temperatures will be one of the key improvements of future setups to more accurately simulate real ocean conditions.

\subsection{Impact of transportation and biological activity on seawater dissolved organic}

\section{matter}

Two selected analyses of DOM are shown here to illustrate various factors which influenced the seawater chemistry: the impact of 1) seawater transportation and 2) phytoplankton growth on the DOM composition. In order to fill the SIO wave channel, 11,800 $\mathrm{L}$ of seawater must be collected from the ocean and transported into the laboratory facility. Due to the handling of the seawater, there is concern that the process may introduce anthropogenic contaminants to the water. Figure S6 is a GCxGC ion chromatogram of seawater obtained from the ocean before addition to the wave channel. Notable in the composition of this seawater is the vast chemical diversity of the sample, as well as a large number of known anthropogenic contaminants, such personal care products and plasticizers. These species are ubiquitous in the 
coastal zone and are unavoidable in mesocosm experiments using coastal seawater.(Gaw et al., 2014; Hermabessiere et al., 2017)

To understand the effect of physical transport on the chemical composition of the seawater during SeaSCAPE, TD-GCxGC-EI-HRToFMS was performed on DOM samples from seawater gathered from the SIO pier before and after transfer to the wave channel on $7 / 23$. As a comparison, we also analyzed DOM of the seawater after the addition of the outdoor phytoplankton culture on $8 / 1$ to understand the influence of biological processes on DOM. Figure $7 \mathrm{~b}$ shows a spectral comparison plot in which the ion intensity chromatogram obtained after the water transfer was subtracted by the chromatogram obtained before the water was transferred. Within the limits of GCxGC sensitivity, we found that few compounds were introduced by the transfer process, with less than $4 \%$ of the ion current in the post transfer sample attributable to species classified as water transfer introduced contaminants (Figure 7a). In contrast to the small changes made by water transfer, a much larger change was measured in DOM after the addition of the outdoor phytoplankton tank to the wave channel, with over $87 \%$ of the GCxGC signal introduced or significantly enhanced after the perturbation (Figure 7a). This is likely due to organic material being actively produced by biological activity in the seawater. Thus, we find that transportation of the seawater to the wave channel has a relatively small effect on seawater composition, especially in contrast to the large changes induced by phytoplankton growth.

\section{4 nSSA Size Distributions and Stability}

The shape of the nSSA size distributions is largely consistent with previous studies of SSA generated by breaking waves (Figure S4) (Prather et al., 2013). However, there was significant temporal variability in the total concentration of particles observed during the experiment. A strong diurnal trend was observed, with higher, more variable concentrations 
observed during the daytime $\left(\mathrm{N}_{\text {day }}=272 \pm 92 \# / \mathrm{cm}^{3}\right)$ and lower, yet more stable concentrations observed during the nighttime $\left(\mathrm{N}_{\text {night }}=199 \pm 70 \# / \mathrm{cm}^{3}\right.$ ) (Figure 8). While seawater temperature can affect the flux of nSSA, the daily changes observed during the SeaSCAPE experiment were likely not large enough to explain the variability in nSSA concentration (Lewis and Schwartz,

800 2004). Typical daily water temperature changes were less $1^{\circ} \mathrm{C}$ (Figure 2), which should correspond to a change in SSA flux of only 2-4\% (Forestieri et al., 2018), whereas the observed change from night to day is, on average, $\sim 37 \%$. The diurnal changes also do not appear to be linked to other changes such as the wave channel lights or the chemical composition of the seawater. Rather, we suspect that the changes in SSA production were driven by the opening and closing of the laboratory doors, which may have affected the air flow and mixing dynamics within the channel headspace. These findings, alongside the results of the sampling port location and depth testing (Figure 5), demonstrate the turbulent mixing within the wave channel headspace, resulting in variable nSSA number concentrations. Further testing and modelling of the wave channel is necessary to fully understand these observations.

\section{5}

\section{Characteristics of hetSSA and SMA produced in the OFRs}

OFRs were used to assess the effects of atmospheric aging on gases and particles emitted from the oceans. While the primary goal of the OFR1 and OFR2 experiments was to assess the effects of photooxidative aging on the properties of SSA (referred to as hetSSA herein), the gases present in the wave channel headspace were not removed and thus also reacted in the OFRs. New particle formation was observed due to the reactions of these gases, as evidenced by the appearance of a large nucleation mode in the aerosol distributions when the OFRs are active (Figure 9a). The formation of SMA in OFR1 and OFR2, both as nucleated particles and via condensation onto SSA, presents a significant challenge for the measurement of hetSSA.

820 Size-resolved measurements can overcome this by simply selecting for particle sizes larger 
than the ultrafine mode $\left(\mathrm{D}_{\mathrm{p}}>\sim 100 \mathrm{~nm}\right)$ and thus presumed to be primary SSA particles. These larger SSA particles may contain secondary species but will have also undergone heterogeneous oxidation by $\mathrm{OH}$ radical and ozone in the OFR. Measurements of the bulk nonrefractory aerosol show significant changes in chemical composition due to oxidation processes

825 in the OFR. In the bulk chemical speciation shown in Figure 9, the relative increase in particulate nitrate, compared to non-refractory particulate chloride, is consistent with heterogeneous reaction of $\mathrm{HNO}_{3}+\mathrm{NaCl} \rightarrow \mathrm{NaNO}_{3}+\mathrm{HCl}$ (Leu et al., 1995). The displacement of chloride for nitrate has been previously observed in coastal sea spray aerosol (Gard et al., 1998) and explored in laboratory experiments (Ault et al., 2013, 2014). In our experiment, this

830 anion substitution indicates that $\mathrm{HNO}_{3}$ is likely produced in the OFR when sampling the wave channel head space air through the oxidation of $\mathrm{NO}_{x}$ to form $\mathrm{HNO}_{3}$.

\subsection{Evidence of abiotic volatile organic compound production from interfacial}

\section{photochemistry}

To test whether VOCs could be produced abiotically by irradiating the organic surface 835 species with sunlight, surface water from the wave channel was exposed to light from a solar simulator and analyzed using a modified gas-phase APCI Orbitrap MS. Shown in Figure 10a, two unique molecular signatures were significantly enhanced upon irradiation compared to other measured m/z signals, as well as three others not shown here (isoprene, dimethyl sulfone, and decadienal only in some days during Bloom 3). Several other species, many unidentified,

840 also increased during this time but exhibited a more gradual increase, indicating a diffusion limited, and therefore most likely biogenic or non-surface related, process (Ciuraru et al., 2015; KAMEYAMA et al., 2011). Two of these species, generated via irradiation, were annotated using tandem MS, showing fragmentation patterns that indicated the presence of phenol, $\mathrm{C}_{6} \mathrm{H}_{6} \mathrm{O}$, and possibly beta-cyclocitral, $\mathrm{C}_{10} \mathrm{H}_{16} \mathrm{O}$. The signal enhancement of these molecules immediately upon irradiation (within 3 minutes), compared to the background dark signal, are 
shown in Figures $9 \mathrm{~b}$ and $9 \mathrm{c}$ respectively. The fragmentation pattern of $\mathrm{C}_{10} \mathrm{H}_{16} \mathrm{O}$ suggests that beta-cyclocitral was the dominant species with this mass-to-charge ratio, but multiple other isobaric species contributed a minor signal. Without an in-depth experiment to constrain the many variables in seawater such as the microbiology, including viruses and enzymes not

850 removed by filtration, or surface tension, it is difficult to make any assumptions about the specific mechanisms responsible for photo-initiated VOC production. Gas-phase APCI Orbitrap MS was shown to successfully ionize a variety of molecular signatures off-gassing from the seawater surface as well as detect changes when the sample was exposed to solar light.

\section{$855 \quad 4.7 \quad$ Relative distribution of morphologies for nascent and hetSSA}

Nascent SSA displayed four unique morphologies including prism-like, core-shell, rounded and aggregates, while hetSSA had two main morphologies: core-shell and rounded (Figure 11a). The morphological categorization was performed qualitatively, analogous to previous studies (Lee et al., 2020b; Ray et al., 2019). Next, the relative distribution of morphologies for nSSA and hetSSA samples were compared (Figure 11b). For the nSSA sample morphologies, the rounded (47\%) was most common, followed by the core-shell (22\%), while prism-like (17\%) and aggregates (14\%) showed similar abundancies. On the other hand, for the hetSSA sample morphologies, core-shell (72\%) was most common, followed by the rounded (28\%) morphology, while no prism-like and aggregates were observed. Overall, SSA aging results in

865 significant increase of the abundance for core-shell morphology, and concomitant decreases in the other morphologies. Additionally, core-shell hetSSA particles showed a thicker coating compared with similar-size nascent core-shell particles. 


\section{Discussion}

\subsection{Wave channel characterization}

A key challenge in ocean-atmosphere simulation experiments is maintaining the highest degree of experimental cleanliness while still capturing the complexity of the natural environment. This challenge is further pressed by the massive volumes of seawater that must be collected and transferred without significant perturbation of the biological assemblages and

875 chemical contamination of the water. For the headspace, large airflows are necessary to offset the flow demand required by online instrumentation and filter sampling. Generating large volumes of high purity air is a significant challenge beyond the removal of particulates. Here we showed that the transfer of seawater from the ocean to the laboratory incurred little contamination; however, there was significant breakthrough of anthropogenic contaminants in

880 the air handling system. The incorporation of the ISV was a critical addition that enabled the measurement of secondary marine aerosol and gases by generating a clean headspace for seawater VOCs to partition into. In the future, advances in economically generating high volumes of particle-free, ultrapure air would be ideal to enable the measurements of seawaterproduced VOCs without the incorporation of secondary chambers.

Systematic testing of the wave channel was conducted to determine the optimal sampling conditions for nascent SSA. This testing showed a clear relationship between the air flow rate in the channel headspace and the measured concentrations of SSA particles, with lower air speeds resulting in higher particle concentrations. However, when the effect of both sampling port location and penetration depth into the channel headspace were evaluated, it was apparent

890 that the nSSA concentrations in the headspace were heterogeneous and highly variable, depending on sampling locations. Further observations during the SeaSCAPE experiment showed a strong diurnal trend in the nSSA concentrations, which may have been caused by the opening and closing of the laboratory doors, creating a change in air pressure in the building. 
Based on these findings, future work is needed to model the fluid dynamics in the wave channel

to understand the mixing and transport of aerosols and gases in the headspace. Additionally, it was observed that nSSA concentrations were typically more stable at night when the laboratory doors were closed, which reduced ambient air movement in the facility. This suggests that future modifications could be made to the wave channel to increase stability in the particle concentrations, such as replacing the open flap at the end of the channel with an improved vent system to control air flow. However, despite the variability in total number concentrations, the shape of the SSA size distributions remained consistent throughout the experiment and agrees well with previous wave channel experiments (Prather et al., 2013). This indicates that the variability in the number concentrations was driven by different degrees of dilution, due to uneven mixing in the headspace, as opposed to variations in the SSA production mechanism

905 or bubble sizes generated by the breaking wave.

\subsection{Biological dynamics during the mesocosm experiment}

One of the most crucial elements of mesocosm experiments to study ocean-atmosphere processes is the stimulation of a phytoplankton bloom (Lee et al., 2015; Pomeroy et al., 2007)

910 involving all the trophic interactions in the microbial loop (Azam et al., 1983; Buchan et al., 2014) between phytoplankton, protozoans, heterotrophic bacteria, and viruses (Lee et al., 2015; Pomeroy et al., 2007). Recent efforts have sought to better reproduce the complexity of marine biology while also accurately measuring the turnover of assemblages to better ascribe changes in seawater, SSA composition and properties, and VOC production. An ongoing challenge is

915 the successful stimulation of authentic mesocosms using natural seawater, which varies in biological composition and may not respond immediately to nutrient amendments. During Bloom 3, the addition of the outdoor tank grown in elevated nutrient conditions and natural sunlight provided a richer starter culture for further growth in the wave channel. In the future, 
enhanced lighting intensity, possibly the usage of actinic flux, will be implemented to allow bloom formation without this added intervention.

The combination of SPCS and microscopy provided a detailed observation of the phytoplankton and microzooplankton dynamic and trophic interactions during the experiment. The phytoplankton assemblages showed a natural succession throughout the course of the experiment, from a diatom-dominated community at the peak of the bloom during the growth phase towards a diatom-aggregate and zooplankton-populated senescent phase. Observation of potential grazing on phytoplankton by microzooplankton and aggregate formation towards the end of the bloom provided insight on the physiological state of the phytoplankton bloom across the experiment (Figure 6). These types of stressors upon phytoplankton may lead to released exudates containing carbon and sulfur that will supply microbial metabolisms, which in turn

930 may influence the production and composition of climate relevant trace gases and the composition of biogenic aerosol (Ksionzek et al., 2016). Future work will compare phytoplankton and VOC concentrations across this study, to screen for specific taxa that may influence VOC production and transformation. The connections between the biological species and the chemical composition of DOM and aerosol will also be the focus of forthcoming

935 SeaSCAPE studies. Further analysis of the functional (e.g. production, enzymes) and community (16S and 18S rDNA amplicon sequencing) adaptation of the marine microbes over the course of the bloom in the water, SML and aerosols will help address some of the chemical changes observed during SeaSCAPE.

\subsection{Photochemical VOC production}

The abiotic production of VOCs from seawater via reactions of surface-present organics with light and oxidants has been recently discussed as a possible source of atmospheric VOCs competitive in emission quantity with marine biology (Novak and Bertram, 2020). Currently, 
only laboratory measurements of abiotic VOC production have been undertaken, with most

945 utilizing SSML or synthetic organic films doped with terrestrially relevant photosensitizers to enhance yields of irradiation-initiated VOC emission (Ciuraru et al., 2015; Trueblood et al., 2019a). Here, using unadulterated seawater from our mesocosm experiments, we show small quantities of abiotic, light-driven VOC generation, including cyclic species, but do not maintain sustained emission compared to other laboratory investigations. Lack of sustained emission is

950 likely due to the limited pool of volatile organic species in seawater, which may have been lost through emission and chemical transformation. While the complex mechanisms that control photoinitiated VOC production are poorly understood, mesocosm experiments serve as a valuable bridge between field and laboratory work towards determining the relative contributions of biotic and abiotic VOC production in the marine environment and will be

955 further pursued.

\subsection{Influence of photochemical aging on SSA composition and secondary}

\section{aerosol formation}

Small SSA can be significantly enriched with organic species (O'Dowd et al., 2004), which 960 influences their reactivity and water uptake properties (Estillore et al., 2017; Ryder et al., 2015). However, the role of atmospheric oxidation processes in transforming the organic chemical composition of SSA remains poorly understood. We found that heterogeneous aging of SSA by $\mathrm{OH}$ radical led to significant changes in its morphology, with the total loss of prism-like and aggregate type particles and a large enhancement in core-shell particles. Increased oxidation of 965 organic aerosol has been shown to increase its viscosity, potentially affecting its phase state (Athanasiadis et al., 2016; Saukko et al., 2012). This process may have contributed to the change in SSA morphologies observed here. An alternative explanation is that coating of secondary organic species onto the SSA altered its morphology. Future studies are necessary 
to understand how both of these processes influence SSA phase and morphology, and the potential influence on the climate relevant properties of SSA, such as ice nucleation, water uptake, and light scattering.

\section{Conclusions}

In summary, wave channels are an important method for understanding the production 975 and properties of marine aerosols and gases under controlled laboratory conditions. Optimization of the wave channel system has enabled even more detailed atmospheric measurements over previous experimental campaigns. In addition, major improvements have been made in the capability to simulate complex seawater biology. The incorporation of oxidation flow reactors has, for the first time, enabled the study of secondary aerosol formation

980 and photochemical aging of SSA during a large-scale wave channel experiment. Preliminary findings from the SeaSCAPE campaign shed light on the photochemical production of VOCs, impact of atmospheric aging on SSA phase and morphology, and the chemical composition of SMA. Future analysis of the SeaSCAPE dataset is expected to give insight to, among other processes, the nature of marine INPs in both freshly emitted and hetSSA; the potential for both

985 SSA and SMA to serve as CCN in the marine atmosphere; the molecular composition of SSA and its links to biological activity; the identity of unique marine VOCs and possible SOA precursors; and the effect of photochemical aging on the chemical composition of marine aerosols. Oceanic emissions of both gases and particles have profound effects on the climate through their interactions with clouds and solar radiation. Laboratory ocean-atmosphere

990 experiments have and will continue to expand our knowledge of marine aerosols and their influence on a changing climate system. 


\section{Acknowledgements}

This material is based upon work supported by the National Science Foundation through the

995 NSF Center for Aerosol Impacts on the Chemistry of the Environment, a Center for Chemical Innovation (CHE-1801971). Thank you to the entire SeaSCAPE team for their hard work throughout the experimental campaign. A full list of participants can be found online: https://caice.ucsd.edu/experiment-campaigns/. We thank Tran Nguyen and the Professor Lihini Aluwihare Lab for analysis of the DOC samples. We would like to acknowledge Dr. Pedro

1000 Belda-Ferre, Professors Elizabeth Stone, Juan Navea, Mike Tauber, Jim Smith, Pieter Dorrestein, Rob Knight, and Farooq Azam for their contributions to the experiment. Special thanks to Joe Mayer for his assistance with fabricating the ISV and the wave channel paddle system; Professor Mark Young for assisting with the paddle software; Dr. Grant Deane and Dr.

Dale Stokes for assistance with wave channel operation; and Rob Klidy and the Hydraulics 1005 Laboratory staff. Thank you to Victor Or for designing the TOC graphic. 


\section{References}

Angle, K. J., Crocker, D. R., Simpson, R. M. C., Mayer, K. J., Garofalo, L. A., Moore, A. N., Garcia, S. L. M., Or, V. W., Srinivasan, S., Farhan, M., Sauer, J. S., Lee, C., Pothier, M. A., Farmer, D. K., Martz, T. R., Bertram, T. H., Cappa, C. D., Prather, K. A. and Grassian, V. H.:

1010 Acidity across the interface: from ocean waters to sea spray aerosol, Proc. Natl. Acad. Sci., Accepted, 2020.

Asher, E. C., Dacey, J. W. H., Jarniková, T. and Tortell, P. D.: Measurement of DMS, DMSO, and DMSP in natural waters by automated sequential chemical analysis, Limnol. Oceanogr. Methods, 13(9), 451-462, doi:https://doi.org/10.1002/lom3.10039, 2015.

1015 Athanasiadis, A., Fitzgerald, C., Davidson, N. M., Giorio, C., Botchway, S. W., Ward, A. D., Kalberer, M., Pope, F. D. and Kuimova, M. K.: Dynamic viscosity mapping of the oxidation of squalene aerosol particles, Phys. Chem. Chem. Phys., 18(44), 30385-30393, doi:10.1039/c6cp05674a, 2016.

Ault, A. P., Guasco, T. L., Ryder, O. S., Baltrusaitis, J., Cuadra-Rodriguez, L. A., Collins, D.

1020 B., Ruppel, M. J., Bertram, T. H., Prather, K. A. and Grassian, V. H.: Inside versus outside: Ion redistribution in nitric acid reacted sea spray aerosol particles as determined by single particle analysis, J. Am. Chem. Soc., 135(39), 14528-14531, doi:10.1021/ja407117x, 2013. Ault, A. P., Guasco, T. L., Baltrusaitis, J., Ryder, O. S., Trueblood, J. V., Collins, D. B., Ruppel, M. J., Cuadra-Rodriguez, L. A., Prather, K. A. and Grassian, V. H.: Heterogeneous reactivity 1025 of nitric acid with nascent sea spray aerosol: Large differences observed between and within individual particles, J. Phys. Chem. Lett., 5(15), 2493-2500, doi:10.1021/jz5008802, 2014.

Azam, F., Fenchel, T., Field, J., Gray, J., Meyer-Reil, L. and Thingstad, F.: The Ecological Role of Water-Column Microbes in the Sea, Mar. Ecol. Prog. Ser., 10, 257-263, doi:10.3354/meps010257, 1983.

1030 Becker, S., Aoyama, M., Woodward, E. M. S., Bakker, K., Coverly, S., Mahaffey, C. and 
Tanhua, T.: GO-SHIP Repeat Hydrography Nutrient Manual: The Precise and Accurate Determination of Dissolved Inorganic Nutrients in Seawater, Using Continuous Flow Analysis Methods, Front. Mar. Sci., 7, doi:10.3389/fmars.2020.581790, 2020.

Boucher, O., Randall, D., Artaxo, P., Bretherton, C., Feingold, G., Forster, P., Kerminen, V.1035 M. V.-M., Kondo, Y., Liao, H., Lohmann, U., Rasch, P., Satheesh, S. K., Sherwood, S., Stevens, B., Zhang, X. Y. and Zhan, X. Y.: Clouds and Aerosols, Clim. Chang. 2013 Phys. Sci. Basis. Contrib. Work. Gr. I to Fifth Assess. Rep. Intergov. Panel Clim. Chang., [Stocker,(Cambridge University Press, Cambridge, United Kingdom and New York, NY, USA), 571-657, doi:10.1017/CBO9781107415324.016, 2013.

1040 Bouvet, M., Hoepffner, N. and Dowell, M. D.: Parameterization of a spectral solar irradiance model for the global ocean using multiple satellite sensors, J. Geophys. Res. Ocean., 107(C12), 8-18, doi:https://doi.org/10.1029/2001JC001126, 2002.

Brussaard, C. P. D.: Optimization of procedures for counting viruses by flow cytometry, , 70(3), 1506-1513, doi:10.1128/AEM.70.3.1506, 2004.

1045 Buchan, A., LeCleir, G. R., Gulvik, C. A. and González, J. M.: Master recyclers: features and functions of bacteria associated with phytoplankton blooms., Nat. Rev. Microbiol., 12(10), 686-698, doi:10.1038/nrmicro3326, 2014.

Carlson, D. J.: Surface microlayer phenolic enrichments indicate sea surface slicks, Nature, 296, 426-429, doi:10.1038/296426a0, 1982.

1050 Carslaw, K. S., Lee, L. a, Reddington, C. L., Pringle, K. J., Rap, a, Forster, P. M., Mann, G. W., Spracklen, D. V, Woodhouse, M. T., Regayre, L. a and Pierce, J. R.: Large contribution of natural aerosols to uncertainty in indirect forcing., Nature, 503(7474), 67-71, doi:10.1038/nature12674, 2013.

Chen, W.-C. and Marcus, R. A.: On the theory of the reaction rate of vibrationally excited CO 1055 molecules with OH radicals, J. Chem. Phys., 124(2), 024306, doi:10.1063/1.2148408, 2006.

Christaki, U., Courties, C., Massana, R., Catala, P., Lebaron, P., Gasol, J. M. and Zubkov, M. 
V.: Optimized routine flow cytometric enumeration of heterotrophic flagellates using SYBR Green I, Limnol. Oceanogr. Methods, 9(AUG), 329-339, doi:10.4319/lom.2011.9.329, 2011a. Christaki, U., Courties, C., Massana, R., Catala, P., Lebaron, P., Gasol, J. M. and Zubkov, M.

V.: Optimized routine flow cytometric enumeration of heterotrophic flagellates using SYBR Green I, Limnol. Oceanogr. Methods, 9, 329-339, doi:10.4319/lom.2011.9.329, 2011b.

Ciuraru, R., Fine, L., Pinxteren, M. Van, D’Anna, B., Herrmann, H. and George, C.: Unravelling New Processes at Interfaces: Photochemical Isoprene Production at the Sea Surface, Environ. Sci. Technol., 49(22), 13199-13205, doi:10.1021/acs.est.5b02388, 2015.

Cochran, R. E., Laskina, O., Jayarathne, T., Laskin, A., Laskin, J., Lin, P., Sultana, C., Lee, C., Moore, K. A., Cappa, C. D., Bertram, T. H., Prather, K. A., Grassian, V. H. and Stone, E. A.: Analysis of Organic Anionic Surfactants in Fine and Coarse Fractions of Freshly Emitted Sea Spray Aerosol, Environ. Sci. Technol., 50(5), 2477-2486, doi:10.1021/acs.est.5b04053, 2016. Collins, D. B., Zhao, D. F., Ruppel, M. J., Laskina, O., Grandquist, J. R., Modini, R. L., Stokes, M. D., Russell, L. M., Bertram, T. H., Grassian, V. H., Deane, G. B. and Prather, K. A.: Direct aerosol chemical composition measurements to evaluate the physicochemical differences between controlled sea spray aerosol generation schemes, Atmos. Meas. Tech., 7(11), 36673683, doi:10.5194/amt-7-3667-2014, 2014.

Crocker, D. R., Hernandez, R. E., Huang, H. D., Pendergraft, M. A., Cao, R., Dai, J., Morris, 1075 C. K., Deane, G. B., Prather, K. A. and Thiemens, M. H.: Biological Influence on 13C and Organic Composition of Nascent Sea Spray Aerosol, ACS Earth Sp. Chem., 4(9), 1686-1699, doi:10.1021/acsearthspacechem.0c00072, 2020.

Cunliffe, M. and Wurl, O.: Sampling the Sea Surface Microlayer., 2015.

DeCarlo, P. F., Kimmel, J. R., Trimborn, A., Northway, M. J., Jayne, J. T., Aiken, A. C., Gonin, 1080 M., Fuhrer, K., Horvath, T., Docherty, K. S., Worsnop, D. R. and Jimenez, J. L.: Fielddeployable, high-resolution, time-of-flight aerosol mass spectrometer, Anal. Chem., 78(24), 8281-8289, doi:10.1021/ac061249n, 2006. 
Demott, P. J., Prenni, A. J., McMeeking, G. R., Sullivan, R. C., Petters, M. D., Tobo, Y., Niemand, M., Möhler, O., Snider, J. R., Wang, Z. and Kreidenweis, S. M.: Integrating 1085 laboratory and field data to quantify the immersion freezing ice nucleation activity of mineral dust particles, Atmos. Chem. Phys., 15(1), 393-409, doi:10.5194/acp-15-393-2015, 2015.

DeMott, P. J., Hill, T. C. J., McCluskey, C. S., Prather, K. A., Collins, D. B., Sullivan, R. C., Ruppel, M. J., Mason, R. H., Irish, V. E., Lee, T., Hwang, C. Y., Rhee, T. S., Snider, J. R., McMeeking, G. R., Dhaniyala, S., Lewis, E. R., Wentzell, J. J. B., Abbatt, J., Lee, C., Sultana, 1090 C. M., Ault, A. P., Axson, J. L., Diaz Martinez, M., Venero, I., Santos-Figueroa, G., Stokes, M. D., Deane, G. B., Mayol-Bracero, O. L., Grassian, V. H., Bertram, T. H., Bertram, A. K., Moffett, B. F. and Franc, G. D.: Sea spray aerosol as a unique source of ice nucleating particles, Proc. Natl. Acad. Sci., 113(21), 201514034, doi:10.1073/pnas.1514034112, 2015.

Dinasquet, J., Tiirola, M. and Azam, F.: Enrichment of Bacterioplankton Able to Utilize One1095 Carbon and Methylated Compounds in the Coastal Pacific Ocean , Front. Mar. Sci. , 5, 307 [online] Available from: https://www.frontiersin.org/article/10.3389/fmars.2018.00307, 2018. Estillore, A. D., Trueblood, J. V and Grassian, V. H.: Atmospheric chemistry of bioaerosols: heterogeneous and multiphase reactions with atmospheric oxidants and other trace gases, , doi:10.1039/c6sc02353c, 2016.

1100 Estillore, A. D., Morris, H. S., Or, V. W., Lee, H. D., Alves, M. R., Marciano, M. A., Laskina, O., Qin, Z., Tivanski, A. V and Grassian, V. H.: Linking hygroscopicity and the surface microstructure of model inorganic salts, simple and complex carbohydrates, and authentic sea spray aerosol particles, Phys. Chem. Chem. Phys., 19(31), 21101-21111, doi:10.1039/C7CP04051B, 2017.

1105 Forestieri, S. D., Moore, K. A., Martinez Borrero, R., Wang, A., Stokes, M. D. and Cappa, C. D.: Temperature and Composition Dependence of Sea Spray Aerosol Production, Geophys. Res. Lett., 45(14), 7218-7225, doi:10.1029/2018GL078193, 2018.

Gabey, A. M., Stanley, W. R., Gallagher, M. W. and Kaye, P. H.: The fluorescence properties 
of aerosol larger than $0.8 \mu$ in urban and tropical rainforest locations, Atmos. Chem. Phys., 1110 11(11), 5491-5504, doi:10.5194/acp-11-5491-2011, 2011.

Gard, E., Mayer, J. E., Morrical, B. D., Dienes, T., Fergenson, D. P. and Prather, K. a: Realtime analysis of individual atmospheric aerosol particles: Design and performance of a portable ATOFMS, Anal. Chem., 69(20), 4083-4091, doi:10.1021/ac970540n, 1997.

Gard, E. E., Kleeman, M. J., Gross, D. S., Hughes, L. S., Allen, J. O., Morrical, B. D.,

1115 Fergenson, D. P., Dienes, T., Gälli, M. E., Johnson, R. J., Cass, G. R. and Prather, K. A.: Direct observation of heterogeneous chemistry in the atmosphere, Science (80-. )., 279(5354), 11841187, doi:10.1126/science.279.5354.1184, 1998.

Gasol, J. M. and Del Giorgio, P. A.: Using flow cytometry for counting natural planktonic bacteria and understanding the structure of planktonic bacterial communities, Sci. Mar., 64(2),

1120 197-224, doi:10.3989/scimar.2000.64n2197, 2000.

Gaw, S., Thomas, K. V. and Hutchinson, T. H.: Sources, impacts and trends of pharmaceuticals in the marine and coastal environment, Philos. Trans. R. Soc. B Biol. Sci., 369(1656), doi:10.1098/rstb.2013.0572, 2014.

Gherman, T., Venables, D. S., Vaughan, S., Orphal, J. and Ruth, A. A.: Incoherent Broadband

1125 Cavity-Enhanced Absorption Spectroscopy in the near-Ultraviolet: Application to HONO and NO2, Environ. Sci. Technol., 42(3), 890-895, doi:10.1021/es0716913, 2008.

Gong, S. L., Barrie, L. A. and Lazare, M.: Canadian Aerosol Module (CAM): A size-segregated simulation of atmospheric aerosol processes for climate and air quality models 2. Global seasalt aerosol and its budgets, J. Geophys. Res. Atmos., 107(24), 1-14, 1130 doi:10.1029/2001JD002004, 2002.

Guillard, R. R. L. and Ryther, J. H.: Studies of Marine Planktonic Diatoms, Can. J. Microbiol., 8(2), 229-238, 1962.

Hales, B., Chipman, D. and Takahashi, T.: High-frequency measurement of partial pressure and total concentration of carbon dioxide in seawater using microporous hydrophobic 
1135 membrane contactors, Limnol. Oceanogr. Methods, 2(11), 356-364, doi:https://doi.org/10.4319/lom.2004.2.356, 2004.

Hatch, L. E., Jen, C. N., Kreisberg, N. M., Selimovic, V., Yokelson, R. J., Stamatis, C., York, R. A., Foster, D., Stephens, S. L., Goldstein, A. H. and Barsanti, K. C.: Highly Speciated Measurements of Terpenoids Emitted from Laboratory and Mixed-Conifer Forest Prescribed 1140 Fires, Environ. Sci. Technol., 53(16), 9418-9428, doi:10.1021/acs.est.9b02612, 2019.

Hering, S. V., Spielman, S. R. and Lewis, G. S.: Moderated, water-based, condensational particle growth in a laminar flow, Aerosol Sci. Technol., 48(4), 401-408, doi:10.1080/02786826.2014.881460, 2014.

Hering, S. V., Lewis, G. S., Spielman, S. R. and Eiguren-Fernandez, A.: A MAGIC concept

1145 for self-sustained, water-based, ultrafine particle counting, Aerosol Sci. Technol., 53(1), 6372, doi:10.1080/02786826.2018.1538549, 2019.

Hermabessiere, L., Dehaut, A., Paul-Pont, I., Lacroix, C., Jezequel, R., Soudant, P. and Duflos, G.: Occurrence and effects of plastic additives on marine environments and organisms: A review, Chemosphere, 182, 781-793, doi:10.1016/j.chemosphere.2017.05.096, 2017.

1150 Hettiyadura, A. P. S., Jayarathne, T., Baumann, K., Goldstein, A. H., De Gouw, J. A., Koss, A., Keutsch, F. N., Skog, K. and Stone, E. A.: Qualitative and quantitative analysis of atmospheric organosulfates in Centreville, Alabama, Atmos. Chem. Phys., 17(2), 1343-1359, doi:10.5194/acp-17-1343-2017, 2017.

Holm-Hansen, O., Lorenzen, C. J., Holmes, R. W. and Strickland, J. D. H.: Fluorometric

1155 Determination of Chlorophyll, ICES J. Mar. Sci., 30(1), 3-15, doi:10.1093/icesjms/30.1.3, 1965.

Hoppe, H.-G.: Significance of exoenzymatic activities in the ecology of brackish water: measurements by means of methylumbelliferyl-substrates, Mar. Ecol. Prog. Ser., 11(3), 299308, doi:10.3354/meps011299, 1983.

1160 Jain, S. and Petrucci, G. A.: A new method to measure aerosol particle bounce using a cascade 
electrical low pressure impactor, Aerosol Sci. Technol., 49(6), 390-399, doi:10.1080/02786826.2015.1036393, 2015.

KAMEYAMA, S., TANIMOTO, H., INOMATA, S., SUZUKI, K., KOMATSU, D. D., HIROTA, A., KONNO, U. T. A. and TSUNOGAI, U.: Application of PTR-MS to an 1165 incubation experiment of the marine diatom Thalassiosira pseudonana, Geochem. J., 45(5), 355-363, doi:10.2343/geochemj.1.0127, 2011.

Kang, E., Root, M. J. and Brune, W. H.: Introducing the concept of Potential Aerosol Mass (PAM), Atmos. Chem. Phys. Discuss., 7(4), 9925-9972, doi:10.5194/acpd-7-9925-2007, 2007. Kercher, J. P., Riedel, T. P. and Thornton, J. A.: Chlorine activation by N2O5: Simultaneous,

1170 in situ detection of CINO2 and N2O5 by chemical ionization mass spectrometry, Atmos. Meas. Tech., 2(1), 193-204, doi:10.5194/amt-2-193-2009, 2009.

Kim, M. J., Michaud, J. M., Williams, R., Sherwood, B. P., Pomeroy, R., Azam, F., Burkart, M. and Bertram, T. H.: Bacterial-driven production of nitrates in seawater, Geophys. Res. Lett., 42(2), 1-8, doi:10.1002/2014GL062865.Received, 2015.

1175 Kim, M. J., Zoerb, M. C., Campbell, N. R., Zimmermann, K. J., Blomquist, B. W., Huebert, B. J. and Bertram, T. H.: Revisiting benzene cluster cations for the chemical ionization of dimethyl sulfide and select volatile organic compounds, Atmos. Meas. Tech., 9(4), 1473-1484, doi:10.5194/amt-9-1473-2016, 2016.

Krechmer, J., Lopez-Hilfiker, F., Koss, A., Hutterli, M., Stoermer, C., Deming, B., Kimmel,

1180 J., Warneke, C., Holzinger, R., Jayne, J., Worsnop, D., Fuhrer, K., Gonin, M. and De Gouw, J.: Evaluation of a New Reagent-Ion Source and Focusing Ion-Molecule Reactor for Use in Proton-Transfer-Reaction Mass Spectrometry, Anal. Chem., 90(20), 12011-12018, doi:10.1021/acs.analchem.8b02641, 2018.

Ksionzek, K. B., Lechtenfeld, O. J., McCallister, S. L., Schmitt-Kopplin, P., Geuer, J. K.,

1185 Geibert, W. and Koch, B. P.: Dissolved organic sulfur in the ocean: Biogeochemistry of a petagram inventory, Science (80-. )., 354(6311), 456 LP - 459, doi:10.1126/science.aaf7796, 
2016.

Lambe, A. T., Ahern, A. T., Williams, L. R., Slowik, J. G., Wong, J. P. S., Abbatt, J. P. D., Brune, W. H., Ng, N. L., Wright, J. P., Croasdale, D. R., Worsnop, D. R., Davidovits, P. and

Onasch, T. B.: Characterization of aerosol photooxidation flow reactors: Heterogeneous oxidation, secondary organic aerosol formation and cloud condensation nuclei activity measurements, Atmos. Meas. Tech., 4(3), 445-461, doi:10.5194/amt-4-445-2011, 2011.

Lavi, A., Vermeuel, M. P., Novak, G. A. and Bertram, T. H.: The sensitivity of benzene cluster cation chemical ionization mass spectrometry to select biogenic terpenes, Atmos. Meas. Tech.

1195 Discuss., 3251-3262, doi:10.5194/amt-2017-408, 2017.

Lee, C., Sultana, C. M., Collins, D. B., Santander, M. V., Axson, J. L., Malfatti, F., Cornwell, G. C., Grandquist, J. R., Deane, G. B., Stokes, M. D., Azam, F., Grassian, V. H. and Prather, K. a.: Advancing Model Systems for Fundamental Laboratory Studies of Sea Spray Aerosol Using the Microbial Loop, J. Phys. Chem. A, 150805131932006, doi:10.1021/acs.jpca.5b03488, 2015.

Lee, H. D., Ray, K. K. and Tivanski, A. V.: Solid, Semisolid, and Liquid Phase States of Individual Submicrometer Particles Directly Probed Using Atomic Force Microscopy, Anal. Chem., 89(23), 12720-12726, doi:10.1021/acs.analchem.7b02755, 2017.

Lee, H. D., Kaluarachchi, C. P., Hasenecz, E. S., Zhu, J. Z., Popa, E., Stone, E. A. and Tivanski, 1205 A. V.: Effect of dry or wet substrate deposition on the organic volume fraction of core-shell aerosol particles, Atmos. Meas. Tech., 12(3), 2033-2042, doi:10.5194/amt-12-2033-2019, 2019.

Lee, H. D., Morris, H. S., Laskina, O., Sultana, C. M., Lee, C., Jayarathne, T., Cox, J. L., Wang, X., Hasenecz, E. S., Demott, P. J., Bertram, T. H., Cappa, C. D., Stone, E. A., Prather, K. A.,

Grassian, V. H. and Tivanski, A. V.: Organic Enrichment, Physical Phase State, and Surface Tension Depression of Nascent Core-Shell Sea Spray Aerosols during Two Phytoplankton Blooms, ACS Earth Sp. Chem., 4(4), 650-660, doi:10.1021/acsearthspacechem.0c00032, 
2020a.

Lee, H. D., Wigley, S., Lee, C., Or, V. W., Hasenecz, E. S., Stone, E. A., Grassian, V. H.,

1215 Prather, K. A. and Tivanski, A. V.: Physicochemical Mixing State of Sea Spray Aerosols: Morphologies Exhibit Size Dependence, ACS Earth Sp. Chem., 4(9), 1604-1611, doi:10.1021/acsearthspacechem.0c00153, $2020 \mathrm{~b}$.

Leu, M. T., Timonen, R. S., Keyser, L. F. and Yung, Y. L.: Heterogeneous reactions of $\mathrm{HNO} 3(\mathrm{~g})+\mathrm{NaCl}(\mathrm{s}) \rightarrow \mathrm{HCl}(\mathrm{g})+\mathrm{NaNO} 3(\mathrm{~s})$ and $\mathrm{N} 2 \mathrm{O} 5(\mathrm{~g})+\mathrm{NaCl}(\mathrm{s}) \rightarrow \mathrm{ClNO} 2(\mathrm{~g})+\mathrm{NaNO} 3(\mathrm{~s})$,

1220 J. Phys. Chem., 99(35), 13203-13212, doi:10.1021/j100035a026, 1995.

Levine, N. M., Varaljay, V. A., Toole, D. A., Dacey, J. W. H., Doney, S. C. and Moran, M. A.: Environmental, biochemical and genetic drivers of DMSP degradation and DMS production in the Sargasso Sea, Environ. Microbiol., 14(5), 1210-1223, doi:https://doi.org/10.1111/j.14622920.2012.02700.x, 2012.

1225 Lewis, E. R. and Schwartz, S. E.: Sea Salt Aerosol Production: Mechanisms, Methods, Measurements, and Models--A Critical Review, American Geophysical Union, Washington D.C., 2004.

Lopez-Hilfiker, F. D., Pospisilova, V., Huang, W., Kalberer, M., Mohr, C., Stefenelli, G., Thornton, J. A., Baltensperger, U., Prevot, A. S. H. and Slowik, J. G.: An Extractive 1230 Electrospray Ionization Time-of-Flight Mass Spectrometer (EESI-TOF) for online measurement of atmospheric aerosol particles, Atmos. Meas. Tech. Discuss., 1-40, doi:10.5194/amt-2019-45, 2019.

Lopez-Yglesias, X. F., Yeung, M. C., Dey, S. E., Brechtel, F. J. and Chan, C. K.: Performance evaluation of the Brechtel Mfg. Humidified Tandem Differential Mobility Analyzer (BMI

1235 HTDMA) for studying hygroscopic properties of aerosol particles, Aerosol Sci. Technol., 48(9), 969-980, doi:10.1080/02786826.2014.952366, 2014.

Mael, L. E., Busse, H. and Grassian, V. H.: Measurements of Immersion Freezing and Heterogeneous Chemistry of Atmospherically Relevant Single Particles with Micro-Raman 
Spectroscopy, Anal. Chem., 91(17), 11138-11145, doi:10.1021/acs.analchem.9b01819, 2019.

Marie, D., Partensky, F., Jacquet, S. and Vaulot, D.: Enumeration and cell cycle analysis of natural populations of marine picoplankton by flow cytometry using the nucleic acid stain SYBR Green I, Appl. Environ. Microbiol., 63(1), 186-193, doi:10.1128/aem.63.1.186193.1997, 1997.

Marie, D., Rigaut-Jalabert, F. and Vaulot, D.: An improved protocol for flow cytometry

1245 analysis of phytoplankton cultures and natural samples, Cytom. Part A, 85(11), 962-968, doi:10.1002/cyto.a.22517, 2014.

Mayer, K. J., Sauer, J. S., Dinasquet, J. and Prather, K. A.: CAICE Studies: Insights from a Decade of Ocean - Atmosphere Experiments in the Laboratory, , doi:10.1021/acs.accounts.0c00504, 2020a.

1250 Mayer, K. J., Wang, X., Santander, M. V, Mitts, B. A., Sauer, J. S., Sultana, C. M., Cappa, C. D. and Prather, K. A.: Secondary Marine Aerosol Plays a Dominant Role over Primary Sea Spray Aerosol in Cloud Formation, ACS Cent. Sci., doi:10.1021/acscentsci.0c00793, 2020b.

Michaud, J. M., Thompson, L. R., Kaul, D., Espinoza, J. L., Richter, R. A., Xu, Z. Z., Lee, C., Pham, K. M., Beall, C. M., Malfatti, F., Azam, F., Knight, R., Burkart, M. D., Dupont, C. L. 1255 and Prather, K. A.: Taxon-specific aerosolization of bacteria and viruses in an experimental ocean-atmosphere mesocosm, Nat. Commun., 9(1), doi:10.1038/s41467-018-04409-z, 2018. Minich, J. J., Zhu, Q., Janssen, S., Hendrickson, R., Amir, A., Vetter, R., Hyde, J., Doty, M. M., Stillwell, K., Benardini, J., Kim, J. H., Allen, E. E., Venkateswaran, K. and Knight, R.: KatharoSeq Enables High-Throughput Microbiome Analysis from Low-Biomass Samples, 1260 edited by M. J. McFall-Ngai, mSystems, 3(3), e00218-17, doi:10.1128/mSystems.00218-17, 2018.

Noble, R. T. and Fuhrman, J. A.: Use of SYBR Green I for rapid epifluorescence counts of marine viruses and bacteria, Aquat. Microb. Ecol., 14(2), 113-118, doi:10.3354/ame014113, 1998. 
Novak, G. A. and Bertram, T. H.: Reactive VOC Production from Photochemical and Heterogeneous Reactions Occurring at the Air-Ocean Interface, Acc. Chem. Res., 53(5), 10141023, doi:10.1021/acs.accounts.0c00095, 2020.

O'Dowd, C. D. and de Leeuw, G.: Marine aerosol production: a review of the current knowledge, Philos. Trans. R. Soc. A Math. Phys. Eng. Sci., 365(1856), 1753-1774, doi:10.1098/rsta.2007.2043, 2007.

O’Dowd, C. D., Facchini, M. C., Cavalli, F., Ceburnis, D., Mircea, M., Decesari, S., Fuzzi, S., Yoon, Y. J. and Putaud, J.-P.: Biogenically driven organic contribution to marine aerosol., Nature, 431(7009), 676-680, doi:10.1038/nature02959, 2004.

Olson, R. J., Chisholm, S. W., Zettler, E. R. and Armbrust, E. V.: Pigments, size, and distributions of Synechococcus in the North Atlantic and Pacific Oceans, Limnol. Oceanogr., 35(1), 45-58, doi:10.4319/1o.1990.35.1.0045, 1990.

Or, V. W., Estillore, A. D., Tivanski, A. V. and Grassian, V. H.: Lab on a tip: Atomic force microscopy-photothermal infrared spectroscopy of atmospherically relevant organic/inorganic aerosol particles in the nanometer to micrometer size range, Analyst, 143(12), 2765-2774, doi:10.1039/c8an00171e, 2018.

Orenstein, E. C., Ratelle, D., Briseño-Avena, C., Carter, M., Franks, P. J. S., Jaffe, J. S. and Roberts, P. L. D.: The Scripps Plankton Camera system: a framework and platform for in situ microscopy, Limnol. Oceanogr. Methods, submitted, doi:10.1002/lom3.10394, 2020.

Patterson, J. P., Collins, D. B., Michaud, J. M., Axson, J. L., Sultana, C. M., Moser, T., Dommer, A. C., Conner, J., Grassian, V. H., Stokes, M. D., Deane, G. B., Evans, J. E., Burkart, M. D., Prather, K. A. and Gianneschi, N. C.: Sea Spray Aerosol Structure and Composition Using Cryogenic Transmission Electron Microscopy., ACS Cent. Sci., 2(1), 40-47, doi:10.1021/acscentsci.5b00344, 2016.

Perkins, R. J., Gillette, S. M., Hill, T. C. J. and Demott, P. J.: The Labile Nature of Ice

Nucleation by Arizona Test Dust, ACS Earth Sp. Chem., 4(1), 133-141, 
doi:10.1021/acsearthspacechem.9b00304, 2020.

Peters, T. M. and Leith, D.: Concentration measurement and counting efficiency of the aerodynamic particle sizer 3321, J. Aerosol Sci., 34(5), 627-634, doi:10.1016/S00218502(03)00030-2, 2003.

1295 Petras, D., Koester, I., Da Silva, R., Stephens, B. M., Haas, A. F., Nelson, C. E., Kelly, L. W., Aluwihare, L. I. and Dorrestein, P. C.: High-Resolution Liquid Chromatography Tandem Mass Spectrometry Enables Large Scale Molecular Characterization of Dissolved Organic Matter , Front. Mar. Sci. , 4, 405 [online] Available from: https://www.frontiersin.org/article/10.3389/fmars.2017.00405, 2017.

1300 Pomeroy, L. R., le Williams, P. J. B., Azam, F. and Hobbie, J. E.: The microbial loop, Oceanography, 20(SPL.ISS. 2), 28-33, doi:10.5670/oceanog.2007.45, 2007.

Prather, K. a, Bertram, T. H., Grassian, V. H., Deane, G. B., Stokes, M. D., Demott, P. J., Aluwihare, L. I., Palenik, B. P., Azam, F., Seinfeld, J. H., Moffet, R. C., Molina, M. J., Cappa, C. D., Geiger, F. M., Roberts, G. C., Russell, L. M., Ault, A. P., Baltrusaitis, J., Collins, D. B., 1305 Corrigan, C. E., Cuadra-Rodriguez, L. a, Ebben, C. J., Forestieri, S. D., Guasco, T. L., Hersey, S. P., Kim, M. J., Lambert, W. F., Modini, R. L., Mui, W., Pedler, B. E., Ruppel, M. J., Ryder, O. S., Schoepp, N. G., Sullivan, R. C. and Zhao, D.: Bringing the ocean into the laboratory to probe the chemical complexity of sea spray aerosol., Proc. Natl. Acad. Sci. U. S. A., 110(19), 7550-5, doi:10.1073/pnas.1300262110, 2013.

1310 Quinn, P. K., Collins, D. B., Grassian, V. H., Prather, K. A. and Bates, T. S.: Chemistry and Related Properties of Freshly Emitted Sea Spray Aerosol, Chem. Rev., 115(10), 4383-4399, doi:10.1021/cr500713g, 2015.

Ray, K. K., Lee, H. D., Gutierrez, M. A., Chang, F. J. and Tivanski, A. V.: Correlating 3D Morphology, Phase State, and Viscoelastic Properties of Individual Substrate-Deposited 1315 Particles, Anal. Chem., 91(12), 7621-7630, doi:10.1021/acs.analchem.9b00333, 2019.

Roberts, G. C. and Nenes, A.: A continuous-flow streamwise thermal-gradient CCN chamber 
for atmospheric measurements, Aerosol Sci. Technol., 39(3), 206-221, doi:10.1080/027868290913988, 2005.

Roveretto, M., Li, M., Hayeck, N., Brüggemann, M., Emmelin, C., Perrier, S. and George, C.:

Real-Time Detection of Gas-Phase Organohalogens from Aqueous Photochemistry Using Orbitrap Mass Spectrometry, ACS Earth Sp. Chem., 3(3), 329-334, doi:10.1021/acsearthspacechem.8b00209, 2019.

Ryder, O. S., Campbell, N. R., Morris, H., Forestieri, S., Ruppel, M. J., Cappa, C., Tivanski, A., Prather, K. and Bertram, T. H.: Role of Organic Coatings in Regulating N2O5 Reactive 1325 Uptake to Sea Spray Aerosol, J. Phys. Chem. A, 119(48), 11683-11692, doi:10.1021/acs.jpca.5b08892, 2015.

Saukko, E., Lambe, A. T., Massoli, P., Koop, T., Wright, J. P., Croasdale, D. R., Pedernera, D. A., Onasch, T. B., Laaksonen, A., Davidovits, P., Worsnop, D. R. and Virtanen, A.: Humiditydependent phase state of SOA particles from biogenic and anthropogenic precursors, Atmos. Chem. Phys., 12(16), 7517-7529, doi:10.5194/acp-12-7517-2012, 2012.

Schneider, S. R., Collins, D. B., Lim, C. Y., Zhu, L. and Abbatt, J. P. D.: Formation of Secondary Organic Aerosol from the Heterogeneous Oxidation by Ozone of a Phytoplankton Culture, ACS Earth Sp. Chem., 3(10), 2298-2306, doi:10.1021/acsearthspacechem.9b00201, 2019.

1335 Shen, S., Jaques, P. A., Zhu, Y., Geller, M. D. and Sioutas, C.: Evaluation of the SMPS-APS system as a continuous monitor for measuring PM2.5, PM10 and coarse (PM2.5-10) concentrations, Atmos. Environ., 36(24), 3939-3950, doi:10.1016/S1352-2310(02)00330-8, 2002.

Smith, D. and Azam, F.: A simple, economical method for measuring bacterial protein synthesis rates in seawater using 3H-leucine, Mar. Microb. food webs, 6(2), 107-114, 1992.

Smith, J. N., Moore, K. F., McMurry, P. H. and Eisele, F. L.: Atmospheric Measurements of Sub-20 nm Diameter Particle Chemical Composition by Thermal Desorption Chemical 
Ionization Mass Spectrometry, Aerosol Sci. Technol., 38(2), 100-110, doi:10.1080/02786820490249036, 2004.

1345 Stokes, M. D., Deane, G. B., Prather, K., Bertram, T. H., Ruppel, M. J., Ryder, O. S., Brady, J. M. and Zhao, D.: A Marine Aerosol Reference Tank system as a breaking wave analogue for the production of foam and sea-spray aerosols, Atmos. Meas. Tech., 6(4), 1085-1094, doi:10.5194/amt-6-1085-2013, 2013.

Stokes, M. D., Deane, G., Collins, D. B., Cappa, C., Bertram, T., Dommer, A., Schill, S.,

1350 Forestieri, S. and Survilo, M.: A miniature Marine Aerosol Reference Tank (miniMART) as a compact breaking wave analogue, Atmos. Meas. Tech., 9(9), 4257-4267, doi:10.5194/amt-94257-2016, 2016.

Stubbins, A. and Dittmar, T.: Low volume quantification of dissolved organic carbon and dissolved nitrogen, Limnol. Oceanogr. Methods, 10(5), 347-352, 1355 doi:10.4319/lom.2012.10.347, 2012.

Trueblood, J. V., Estillore, A. D., Lee, C., Dowling, J. A., Prather, K. A. and Grassian, V. H.: Heterogeneous Chemistry of Lipopolysaccharides with Gas-Phase Nitric Acid: Reactive Sites and Reaction Pathways, J. Phys. Chem. A, 120(32), 6444-6450, doi:10.1021/acs.jpca.6b07023, 2016.

1360 Trueblood, J. V., Alves, M. R., Power, D., Santander, M. V., Cochran, R. E., Prather, K. A. and Grassian, V. H.: Shedding Light on Photosensitized Reactions within Marine-Relevant Organic Thin Films, ACS Earth Sp. Chem., 3(8), 1614-1623, doi:10.1021/acsearthspacechem.9b00066, 2019a.

Trueblood, J. V., Wang, X., Or, V. W., Alves, M. R., Santander, M. V., Prather, K. A. and

1365 Grassian, V. H.: The Old and the New: Aging of Sea Spray Aerosol and Formation of Secondary Marine Aerosol through OH Oxidation Reactions, ACS Earth Sp. Chem., 3(10), 2307-2314, doi:10.1021/acsearthspacechem.9b00087, 2019b.

Utermöhl, H.: Neue Wege in der quantitativen Erfassung des Plankton.(Mit besonderer 
Berücksichtigung des Ultraplanktons.), SIL Proceedings, 1922-2010, 5(2), 567-596, doi:10.1080/03680770.1931.11898492, 1931.

Voisin, D., Smith, J. N., Sakurai, H., McMurry, P. H. and Eisele, F. L.: Thermal desorption chemical ionization mass spectrometer for ultrafine particle chemical composition, Aerosol Sci. Technol., 37(6), 471-475, doi:10.1080/02786820300959, 2003.

Wakeham, S. G., Canuel, E. A. and Doering, P. H.: Geochemistry of volatile organic compounds in seawater: Mesocosm experiments with 14C-model compounds, Geochim. Cosmochim. Acta, 50(6), 1163-1172, doi:10.1016/0016-7037(86)90399-6, 1986.

Walters, W., Hyde, E. R., Berg-Lyons, D., Ackermann, G., Humphrey, G., Parada, A., Gilbert, J. A., Jansson, J. K., Caporaso, J. G., Fuhrman, J. A., Apprill, A. and Knight, R.: Improved Bacterial 16S rRNA Gene (V4 and V4-5) and Fungal Internal Transcribed Spacer Marker Gene

1380 Primers for Microbial Community Surveys, edited by H. Bik, mSystems, 1(1), e00009-15, doi:10.1128/mSystems.00009-15, 2016.

Wang, X., Sultana, C. M., Trueblood, J., Hill, T. C. J., Malfatti, F., Lee, C., Laskina, O., Moore, K. A., Beall, C. M., McCluskey, C. S., Cornwell, G. C., Zhou, Y., Cox, J. L., Pendergraft, M. A., Santander, M. V., Bertram, T. H., Cappa, C. D., Azam, F., DeMott, P. J., Grassian, V. H. 1385 and Prather, K. A.: Microbial Control of Sea Spray Aerosol Composition: A Tale of Two Blooms, ACS Cent. Sci., 1(3), 124-131, doi:10.1021/acscentsci.5b00148, 2015.

Wang, X., Deane, G. B., Moore, K. A., Ryder, O. S., Stokes, M. D., Beall, C. M., Collins, D. B., Santander, M. V., Burrows, S. M., Sultana, C. M. and Prather, K. A.: The role of jet and film drops in controlling the mixing state of submicron sea spray aerosol particles, Proc. Natl. Acad. Sci. U. S. A., 114(27), 6978-6983, doi:10.1073/pnas.1702420114, 2017.

Wei, Y., Jiao, Y., An, D., Li, D., Li, W. and Wei, Q.: Review of dissolved oxygen detection technology: From laboratory analysis to online intelligent detection, Sensors (Switzerland), 19(18), doi:10.3390/s19183995, 2019.

Wolfe, G. M., Nicely, J. M., St. Clair, J. M., Hanisco, T. F., Liao, J., Oman, L. D., Brune, W. 
1395 B., Miller, D., Thames, A., González Abad, G., Ryerson, T. B., Thompson, C. R., Peischl, J., McKain, K., Sweeney, C., Wennberg, P. O., Kim, M., Crounse, J. D., Hall, S. R., Ullmann, K., Diskin, G., Bui, P., Chang, C. and Dean-Day, J.: Mapping hydroxyl variability throughout the global remote troposphere via synthesis of airborne and satellite formaldehyde observations, Proc. Natl. Acad. Sci., 116(23), 11171 LP - 11180, doi:10.1073/pnas.1821661116, 2019.

1400 Worton, D. R., Decker, M., Isaacman-VanWertz, G., Chan, A. W. H., Wilson, K. R. and Goldstein, A. H.: Improved molecular level identification of organic compounds using comprehensive two-dimensional chromatography, dual ionization energies and high resolution mass spectrometry, Analyst, 142(13), 2395-2403, doi:10.1039/c7an00625j, 2017. 


\section{Tables}

\begin{tabular}{|c|c|c|c|}
\hline Bloom Cycle & Water Fill Date & Nutrient Addition Date & Nutrient Concentration \\
\hline Bloom 1 & $7 / 1 / 2019$ & $7 / 4 / 2019$ & $\mathrm{f} / 2$ nutrients + silicates \\
\hline Bloom 2 & $7 / 12 / 2019$ & $7 / 14 / 2019$ & $\mathrm{f} / 20$ nutrients + silicates \\
\hline \multirow{2}{*}{ Bloom 3 } & \multirow{2}{*}{$7 / 23 / 2019$} & $7 / 25 / 2019$ & $\mathrm{f} / 20$ nutrients $+\mathrm{f} / 40$ silicates \\
\cline { 3 - 4 } & & $7 / 26 / 2019$ & Addition silicates, to f/20 total \\
\cline { 3 - 4 } & & $8 / 1 / 2019$ & $\begin{array}{c}\text { Additional nutrients and silicates, to total } \\
\text { concentration of } \mathrm{f} / 2 \text { for both }\end{array}$ \\
\hline
\end{tabular}

Table 1: Summary of seawater collection and nutrient additions during the three SeaSCAPE bloom cycles. 


\begin{tabular}{|c|c|c|c|c|}
\hline Measurement & Technique & $\begin{array}{c}\text { Sample } \\
\text { type }\end{array}$ & $\begin{array}{l}\text { Sampling } \\
\text { Interval }\end{array}$ & Reference \\
\hline \multirow{3}{*}{$\begin{array}{l}\text { Dry particle size } \\
\text { distributions from } 5 \\
\text { nm to } 20 \mu \mathrm{m}\end{array}$} & $\begin{array}{c}\text { Scanning Mobility Particle } \\
\text { Sizer (SMPS, TSI Inc) } \\
\end{array}$ & $\mathrm{N}, \mathrm{H}, \mathrm{S}$ & $2-5 \min$ & $\begin{array}{l}\text { (Shen et al., } \\
\text { 2002) }\end{array}$ \\
\hline & $\begin{array}{l}\text { Aerodynamic Particle Sizer } \\
\text { (APS 3321, TSI inc) }\end{array}$ & $\mathrm{N}, \mathrm{H}$ & $1 \mathrm{~min}$ & $\begin{array}{l}\text { (Peters and } \\
\text { Leith, 2003) }\end{array}$ \\
\hline & $\begin{array}{c}\text { Scanning Electrical Mobility } \\
\text { Spectrometer (SEMS, } \\
\text { Brechtel) }\end{array}$ & $\mathrm{N}, \mathrm{H}$ & $5 \min$ & $\begin{array}{l}\text { (Lopez- } \\
\text { Yglesias et al., } \\
\text { 2014) }\end{array}$ \\
\hline Total particle number & $\begin{array}{c}\text { Condensation Particle Counter } \\
(\mathrm{CPC})\end{array}$ & $\mathrm{N}$ & $1 \mathrm{~s}$ & $\begin{array}{l}\text { (Hering et al., } \\
2019)\end{array}$ \\
\hline $\begin{array}{c}\text { Single particle } \\
\text { composition and size }\end{array}$ & $\begin{array}{l}\text { Aerosol Time-of-Flight Mass } \\
\text { Spectrometer (ATOFMS) }\end{array}$ & $\mathrm{N}, \mathrm{H}$ & $1 \mathrm{~min}$ & $\begin{array}{c}\text { (Gard et al., } \\
\text { 1997) }\end{array}$ \\
\hline $\begin{array}{l}\text { Size-resolved non- } \\
\text { refractory submicron } \\
\text { aerosol composition } \\
\end{array}$ & $\begin{array}{c}\text { High Resolution Time-of- } \\
\text { Flight Aerosol Mass } \\
\text { Spectrometer (HR-ToF-AMS) }\end{array}$ & $\mathrm{N}, \mathrm{H}, \mathrm{S}$ & $5 \mathrm{~min}$ & $\begin{array}{c}\text { (DeCarlo et al., } \\
\text { 2006) }\end{array}$ \\
\hline $\begin{array}{l}\text { Ultrafine aerosol } \\
\text { chemical composition }\end{array}$ & $\begin{array}{l}\text { Thermal Desorption Chemical } \\
\text { Ionization Mass Spectrometer } \\
\text { (TDCIMS) }\end{array}$ & $\mathrm{N}, \mathrm{S}$ & $\begin{array}{l}\mathrm{N}: 1 \mathrm{~h} \\
\mathrm{~S}: 30 \mathrm{~min}\end{array}$ & $\begin{array}{l}\text { (Smith et al., } \\
\text { 2004; Voisin et } \\
\text { al., 2003) }\end{array}$ \\
\hline $\begin{array}{l}\text { Submicron aerosol } \\
\text { chemical composition }\end{array}$ & $\begin{array}{c}\text { Extractive Electrospray } \\
\text { Ionization Mass Spectrometry } \\
\text { (EESI-MS) }\end{array}$ & $\mathrm{N}, \mathrm{H}, \mathrm{S}$ & $1 \mathrm{~s}$ & $\begin{array}{l}\text { (Lopez-Hilfiker } \\
\text { et al., 2019) }\end{array}$ \\
\hline $\begin{array}{l}\text { Size-resolved cloud } \\
\text { condensation nuclei } \\
\text { activity }\end{array}$ & $\begin{array}{l}\text { Continuous-flow streamwise } \\
\text { thermal-gradient CCN counter }\end{array}$ & $\mathrm{N}, \mathrm{H}, \mathrm{S}$ & $30-60 \mathrm{~min}$ & $\begin{array}{l}\text { (Roberts and } \\
\text { Nenes, 2005) }\end{array}$ \\
\hline $\begin{array}{l}\text { Relative humidity- } \\
\text { dependent aerosol } \\
\text { bounce }\end{array}$ & $\begin{array}{l}\text { Electrical Low Pressure } \\
\text { Impactor (ELPI) }\end{array}$ & $\mathrm{N}, \mathrm{H}, \mathrm{S}$ & $1 \mathrm{~min}$ & $\begin{array}{c}\text { (Jain and } \\
\text { Petrucci, 2015) }\end{array}$ \\
\hline INP concentration & $\begin{array}{c}\text { Continuous-Flow Diffusion } \\
\text { Chamber (CFDC) }\end{array}$ & $\mathrm{N}, \mathrm{H}$ & $5-15 \min$ & $\begin{array}{c}\text { (Demott et al., } \\
2015)\end{array}$ \\
\hline $\begin{array}{l}\text { Size-resolved } \\
\text { fluorescent biological } \\
\text { particle number } \\
\text { concentrations }\end{array}$ & $\begin{array}{l}\text { Wideband Integrated } \\
\text { Bioaerosol Sensor (WIBS) }\end{array}$ & $\mathrm{N}, \mathrm{H}$ & $1 \mathrm{~s}$ & $\begin{array}{l}\text { (Gabey et al., } \\
\text { 2011) }\end{array}$ \\
\hline
\end{tabular}

Table 2: Summary of all online aerosol measurement techniques employed during SeaSCAPE. The sample type is designated by a single letter $(\mathrm{N}=$ Nascent SSA, $\mathrm{H}=$ Heterogeneously-aged 1415 SSA, S = Secondary Marine Aerosol) 


\begin{tabular}{|c|c|c|c|c|c|}
\hline Measurement & $\begin{array}{l}\text { Collection } \\
\text { Technique }\end{array}$ & $\begin{array}{l}\text { Analysis } \\
\text { Technique }\end{array}$ & $\begin{array}{c}\text { Sample } \\
\text { type }\end{array}$ & $\begin{array}{l}\text { Sampling } \\
\text { Interval }\end{array}$ & Reference \\
\hline $\begin{array}{l}\text { INP concentration } \\
\text { and characteristics }\end{array}$ & $\begin{array}{l}\text { Polycarbonate } \\
\text { filters }\end{array}$ & Ice spectrometer & $\mathrm{N}, \mathrm{H}$ & $1-5.5 \mathrm{~h}$ & $\begin{array}{l}\text { (Perkins et al., } \\
2020)\end{array}$ \\
\hline $\begin{array}{l}\text { Size-segregated } \\
\text { organic aerosol } \\
\text { composition }\end{array}$ & $\begin{array}{l}\text { Sioutas } \\
\text { cascade } \\
\text { impactor }\end{array}$ & $\begin{array}{l}\text { High resolution } \\
\text { mass spectrometry }\end{array}$ & $\mathrm{N}, \mathrm{H}$ & $6-12 \mathrm{~h}$ & $\begin{array}{l}\text { (Cochran et al., } \\
\text { 2016; } \\
\text { Hettiyadura et } \\
\text { al., 2017) }\end{array}$ \\
\hline \multirow{2}{*}{$\begin{array}{l}\text { Single particle } \\
\text { morphology, phase } \\
\text { state, organic } \\
\text { volume fraction, } \\
\text { and water uptake }\end{array}$} & \multirow[b]{2}{*}{$\begin{array}{l}\text { MOUDI } \\
\text { impactor }\end{array}$} & $\begin{array}{c}\text { Atomic Force } \\
\text { Microscopy (AFM) }\end{array}$ & $\mathrm{N}, \mathrm{H}$ & $\begin{array}{l}\mathrm{N}: 5-6 \mathrm{~h} \\
\mathrm{H}: 1-2 \mathrm{~h}\end{array}$ & $\begin{array}{c}\text { (Lee et al., } \\
2017,2020 \mathrm{a})\end{array}$ \\
\hline & & $\begin{array}{l}\text { AFM photothermal } \\
\text { infrared } \\
\text { spectroscopy } \\
\text { (AFM-PTIR) }\end{array}$ & $\mathrm{N}, \mathrm{H}$ & $\begin{array}{l}\mathrm{N}: 5-6 \mathrm{~h} \\
\mathrm{H}: 1-2 \mathrm{~h}\end{array}$ & (Or et al., 2018) \\
\hline $\begin{array}{c}\text { Immersion } \\
\text { freezing of single } \\
\text { particles }\end{array}$ & $\begin{array}{l}\text { MOUDI } \\
\text { impactor }\end{array}$ & $\begin{array}{l}\text { Micro-Raman } \\
\text { spectroscopy }\end{array}$ & $\mathrm{N}, \mathrm{H}$ & $1-2 h$ & $\begin{array}{l}\text { (Mael et al., } \\
\text { 2019) }\end{array}$ \\
\hline Aerosol pH & $\begin{array}{l}\text { MOUDI } \\
\text { impactor }\end{array}$ & pH paper & $\mathrm{N}$ & $1-2 \mathrm{~h}$ & $\begin{array}{l}\text { (Angle et al., } \\
2020)\end{array}$ \\
\hline \multirow{2}{*}{$\begin{array}{l}\text { Chemical and } \\
\text { microbial } \\
\text { composition }\end{array}$} & \multirow{2}{*}{$\begin{array}{l}\text { Quarts fiber } \\
\text { filters }\end{array}$} & $\begin{array}{l}\text { High-resolution } \\
\text { mass spectrometry }\end{array}$ & $\mathrm{N}$ & $24 \mathrm{~h}$ & $\begin{array}{c}\text { (Petras et al., } \\
\text { 2017) }\end{array}$ \\
\hline & & $\begin{array}{c}\text { 16S/18S rDNA } \\
\text { sequencing }\end{array}$ & $\mathrm{N}$ & $24 \mathrm{~h}$ & $\begin{array}{c}\text { (Michaud et al., } \\
\text { 2018) }\end{array}$ \\
\hline $\begin{array}{l}\text { Viral and bacterial } \\
\text { abundances }\end{array}$ & Spot sampler & Flow cytometry & $\mathrm{N}$ & $4-6 h$ & $\begin{array}{l}\text { (Brussaard, } \\
\text { 2004; Gasol and } \\
\text { Del Giorgio, } \\
\text { 2000) }\end{array}$ \\
\hline Enzymes activities & Spot sampler & $\begin{array}{l}\text { Fluorogenic } \\
\text { substrates }\end{array}$ & $\mathrm{N}$ & $6 \mathrm{~h}$ & $\begin{array}{c}\text { (Hering et al., } \\
\text { 2014; Hoppe, } \\
\text { 1983) }\end{array}$ \\
\hline $\begin{array}{l}\text { Submicron aerosol } \\
\text { speciated organic } \\
\text { chemical } \\
\text { composition }\end{array}$ & $\begin{array}{l}\text { Quartz fiber } \\
\text { filters }\end{array}$ & $\begin{array}{c}\text { TD-GCxGC-EI- } \\
\text { HRToF-MS }\end{array}$ & $\mathrm{N}$ & $\begin{array}{c}14 \mathrm{~h} / 10 \mathrm{~h} \\
\text { (day/night } \\
\text { ) }\end{array}$ & $\begin{array}{l}\text { (Worton et al., } \\
\text { 2017) }\end{array}$ \\
\hline $\begin{array}{l}\text { Submicron and } \\
\text { Supermicron } \\
\text { Isotopic Analysis }\end{array}$ & $\begin{array}{l}\text { Cyclone and } \\
\text { quartz fiber } \\
\text { filters }\end{array}$ & $\begin{array}{l}\text { MAT } 253 \text { Isotope- } \\
\text { ratio mass } \\
\text { spectrometry } \\
\text { (IRMS) }\end{array}$ & $\mathrm{N}$ & $48 \mathrm{~h}$ & $\begin{array}{l}\text { (Crocker et al., } \\
\text { 2020) }\end{array}$ \\
\hline
\end{tabular}


Table 3: Summary of all offline aerosol measurement techniques employed during SeaSCAPE. The sample type is designated by a single letter $(\mathrm{N}=$ Nascent SSA, $\mathrm{H}=$ Heterogeneously-Aged SSA, S = Secondary Marine Aerosol) 


\begin{tabular}{|c|c|c|c|c|}
\hline Measurement & Technique & $\begin{array}{c}\text { Sample } \\
\text { type }\end{array}$ & $\begin{array}{l}\text { Sampling } \\
\text { Interval }\end{array}$ & Reference \\
\hline \multirow{2}{*}{$\mathrm{O}_{3}$} & $\begin{array}{l}\text { UV absorption, Thermo } \\
\text { Environmental Model 49C }\end{array}$ & $\mathrm{W}$ & $1 \mathrm{~s}$ & N/A \\
\hline & $\begin{array}{c}\text { UV absorption, 2B } \\
\text { Technologies Model } 202\end{array}$ & $\mathrm{~A}, \mathrm{O}$ & $1 \mathrm{~s}$ & N/A \\
\hline $\mathrm{NO}-\mathrm{NO}_{2}-\mathrm{NO}_{x}$ & $\begin{array}{l}\text { Chemiluminescence, Thermo } \\
\text { Environmental Model 42C }\end{array}$ & W,A & $1 \mathrm{~s}$ & N/A \\
\hline $\mathrm{SO}_{2}$ & $\begin{array}{l}\text { Pulsed fluorescence, Thermo } \\
\text { Environmental Model 43iQ }\end{array}$ & W,A & $1 \mathrm{~s}$ & N/A \\
\hline VOCs & $\begin{array}{c}\text { Vocus Proton Transfer } \\
\text { Reaction Mass Spectrometry } \\
\text { (PTR-ToF-MS) }\end{array}$ & W,I,A & $1 \mathrm{~s}$ & $\begin{array}{l}\text { (Krechmer et } \\
\text { al., 2018) }\end{array}$ \\
\hline $\begin{array}{l}\text { Sulfur-containing } \\
\text { VOCs }\end{array}$ & $\begin{array}{c}\text { Chemical Ionization Mass } \\
\text { Spectrometry (benzene reagent } \\
\text { ion, B-CI-ToF-MS) }\end{array}$ & $\mathrm{I}, \mathrm{D}$ & $1 \mathrm{~s}$ & $\begin{array}{l}\text { (Kim et al., } \\
\text { 2016) }\end{array}$ \\
\hline $\begin{array}{l}\text { Speciated VOC's } \\
\text { (Isomer Specific) }\end{array}$ & TD-GCxGC-EI-HRToF-MS & I & $\begin{array}{c}20 \text { min } \\
\text { collection, } \\
\text { every } 1-3 \\
\text { days }\end{array}$ & $\begin{array}{c}\text { (Hatch et al., } \\
\text { 2019) }\end{array}$ \\
\hline $\begin{array}{l}\text { Abiotic photo- } \\
\text { enhanced surface } \\
\text { products }\end{array}$ & $\begin{array}{c}\text { Gas phase modified- } \\
\text { atmospheric pressure chemical } \\
\text { ionization Orbitrap mass } \\
\text { spectrometry (APCI-MS) }\end{array}$ & $\mathrm{B}, \mathrm{L}$ & $24 \mathrm{~h}$ & $\begin{array}{l}\text { (Roveretto et } \\
\text { al., 2019) }\end{array}$ \\
\hline
\end{tabular}

Table 4: Summary of all gas-phase measurement techniques employed during SeaSCAPE. The sample type is designated by a single letter $(\mathrm{W}=$ wave channel headspace, $\mathrm{I}=$ isolated sampling vessel headspace, $\mathrm{D}=$ dissolved gases, $\mathrm{A}=$ air handling system, $\mathrm{O}=\mathrm{OFR}, \mathrm{B}=$ bulk seawater, $\mathrm{L}=\mathrm{SSML})$ 


\begin{tabular}{|c|c|c|c|c|}
\hline Measurement & Technique & $\begin{array}{c}\text { Sample } \\
\text { type }\end{array}$ & $\begin{array}{l}\text { Sampling } \\
\text { Interval }\end{array}$ & Reference \\
\hline \multirow{3}{*}{ Chlorophyll-a } & $\begin{array}{l}\text { Continuous fluorescence } \\
\text { (ESP) }\end{array}$ & B & $1 \mathrm{~min}$ & (Wang et al., 2015) \\
\hline & $\begin{array}{l}\text { Fluorescence } \\
\text { (AquaFluor) }\end{array}$ & $\mathrm{B}$ & $24 \mathrm{~h}$ & (Wang et al., 2015) \\
\hline & Extracted fluorescence & B & $24 \mathrm{~h}$ & $\begin{array}{c}\text { (Holm-Hansen et al., } \\
1965)\end{array}$ \\
\hline Dissolved $\mathrm{O}_{2}$ & $\begin{array}{l}\text { Continuous optical } \\
\text { absorption }\end{array}$ & $\mathrm{B}$ & $1 \mathrm{~min}$ & (Wei et al., 2019) \\
\hline $\begin{array}{l}\text { Bacterial community } \\
\text { composition }\end{array}$ & Amplicon Sequencing & $\mathrm{B}, \mathrm{L}$ & $24 \mathrm{~h}$ & $\begin{array}{l}\text { (Walters et al., } \\
\text { 2016) }\end{array}$ \\
\hline $\begin{array}{c}\text { Heterotrophic bacteria } \\
\text { concentration }\end{array}$ & \multirow{3}{*}{ Flow Cytometry } & $\mathrm{B}, \mathrm{L}$ & $24 \mathrm{~h}$ & $\begin{array}{c}\text { (Gasol and Del } \\
\text { Giorgio, 2000) } \\
\end{array}$ \\
\hline $\begin{array}{c}\text { Virus } \\
\text { concentration }\end{array}$ & & $\mathrm{B}, \mathrm{L}$ & $24 \mathrm{~h}$ & (Brussaard, 2004) \\
\hline $\begin{array}{l}\text { Nano-pico- phytoplankton } \\
\text { and heterotrophic } \\
\text { nanoflagellates } \\
\text { concentration }\end{array}$ & & $\mathrm{B}, \mathrm{L}$ & $24 \mathrm{~h}$ & $\begin{array}{c}\text { (Christaki et al., } \\
\text { 2011b; Marie et al., } \\
\text { 1997) }\end{array}$ \\
\hline \multirow{2}{*}{ Phytoplankton community } & In-situ camera & $\mathrm{B}$ & $10 \mathrm{~Hz}$ & $\begin{array}{c}\text { (Orenstein et al., } \\
2020)\end{array}$ \\
\hline & $\begin{array}{l}\text { Microscopy and } \\
\text { sequencing }\end{array}$ & $\mathrm{B}, \mathrm{L}$ & $24 \mathrm{~h}$ & (Minich et al., 2018) \\
\hline Dissolved organic carbon & $\begin{array}{c}\text { High temperature } \\
\text { catalytic combustion } \\
\text { (Shimadzu TOC-V series } \\
\text { instrument) }\end{array}$ & B & Daily & $\begin{array}{l}\text { (Stubbins and } \\
\text { Dittmar, 2012) }\end{array}$ \\
\hline \multirow{2}{*}{$\begin{array}{l}\text { Speciated DOM organic } \\
\text { compounds }\end{array}$} & HR-ESI-MS & B & $72 \mathrm{~h}$ & $\begin{array}{c}\text { (Trueblood et al., } \\
\text { 2019a) }\end{array}$ \\
\hline & $\begin{array}{c}\text { TD-GCxGC-EI-HRToF- } \\
\text { MS }\end{array}$ & $\mathrm{B}, \mathrm{L}$ & $72 \mathrm{~h}$ & (Worton et al., 2017) \\
\hline $\begin{array}{l}\text { Nutrients }\left(\mathrm{NO}_{3}, \mathrm{NO}_{2}, \mathrm{PO}_{4},\right. \\
\left.\qquad \mathrm{SiO}_{4}, \mathrm{NH}_{4}\right)\end{array}$ & $\begin{array}{l}\text { Seal Analytical } \\
\text { continuous-flow } \\
\text { AutoAnalyzer } 3 \\
\end{array}$ & B & $24 \mathrm{~h}$ & (Becker et al., 2020) \\
\hline
\end{tabular}




\begin{tabular}{|c|c|c|c|c|}
\hline $\begin{array}{c}\text { Alkalinity, Bicarbonate, } \\
\text { Carbonate, Dissolved } \\
\text { Inorganic Carbon, } \\
\text { Dissolved } \mathrm{CO}_{2} \text {, Salinity, } \\
\mathrm{pH}\end{array}$ & $\begin{array}{c}\text { Combined } \mathrm{pCO}_{2} / \mathrm{TCO}_{2} \\
\text { Dual Analyzer }\end{array}$ & B & $1 \mathrm{~Hz}$ & (Hales et al., 2004) \\
\hline Water temperature & Thermocouple (ESP) & $\mathrm{B}$ & $1 \mathrm{~min}$ & (Wang et al., 2015) \\
\hline Enzyme Activity & Fluorogenic Substrates & $\mathrm{B}, \mathrm{L}$ & $24 \mathrm{~h}$ & (Hoppe, 1983) \\
\hline $\begin{array}{l}\text { Bacterial } \\
\text { production/Growth rate }\end{array}$ & H3Leucine incorporation & $\mathrm{B}, \mathrm{L}$ & $24 \mathrm{~h}$ & $\begin{array}{c}\text { (Smith and Azam, } \\
1992 \text { ) }\end{array}$ \\
\hline Methylotrophy & $\begin{array}{l}\text { C14-methanol } \\
\text { incorporation }\end{array}$ & $\mathrm{B}, \mathrm{L}$ & $24 \mathrm{~h}$ & $\begin{array}{c}\text { (Dinasquet et al., } \\
\text { 2018) }\end{array}$ \\
\hline $\begin{array}{l}\text { DMSPp,DMSPd, } \\
\text { [DMS]aq }\end{array}$ & $\begin{array}{l}\text { Cryo Purge and Trap } \\
\text { Benzene CI-ToF-MS }\end{array}$ & B & $24 \mathrm{~h}$ & $\begin{array}{l}\text { (Asher et al., 2015; } \\
\text { Kim et al., 2016) }\end{array}$ \\
\hline $\begin{array}{c}\text { Functional genes and } \\
\text { transcripts } \\
\text { dddP, dmdA }\end{array}$ & $\begin{array}{l}\text { Q-PCR for quantification, } \\
\text { and sequencing }\end{array}$ & $\mathrm{B}, \mathrm{L}$ & $24 \mathrm{~h}$ & (Levine et al., 2012) \\
\hline $\begin{array}{l}\text { INP concentration and } \\
\text { characteristics }\end{array}$ & Ice Spectrometer & $\mathrm{B}, \mathrm{L}$ & $24 \mathrm{~h}$ & (Perkins et al., 2020) \\
\hline Fluorescent DOM & $\begin{array}{c}\text { Fluorescence excitation } \\
\text { emission matrix } \\
\text { spectroscopy (EEMS) }\end{array}$ & $\mathrm{B}, \mathrm{L}$ & $24 \mathrm{~h}$ & $\begin{array}{c}\text { (Trueblood et al., } \\
\text { 2019a) }\end{array}$ \\
\hline $\begin{array}{l}\text { HONO production from } \\
\text { DOM }\end{array}$ & $\begin{array}{l}\text { Incoherent broadband } \\
\text { cavity-enhanced } \\
\text { absorption spectroscopy } \\
\text { (IBBCEAS) }\end{array}$ & B & $\begin{array}{l}\text { End of } \\
\text { Bloom } 3 \\
\text { only }\end{array}$ & $\begin{array}{c}\text { (Gherman et al., } \\
\text { 2008) }\end{array}$ \\
\hline
\end{tabular}

Table 5: Summary of all seawater and SSML measurements collected during SeaSCAPE. The sample type is designated by a single letter $(\mathrm{L}=\mathrm{SSML}, \mathrm{B}=$ bulk seawater $)$ 

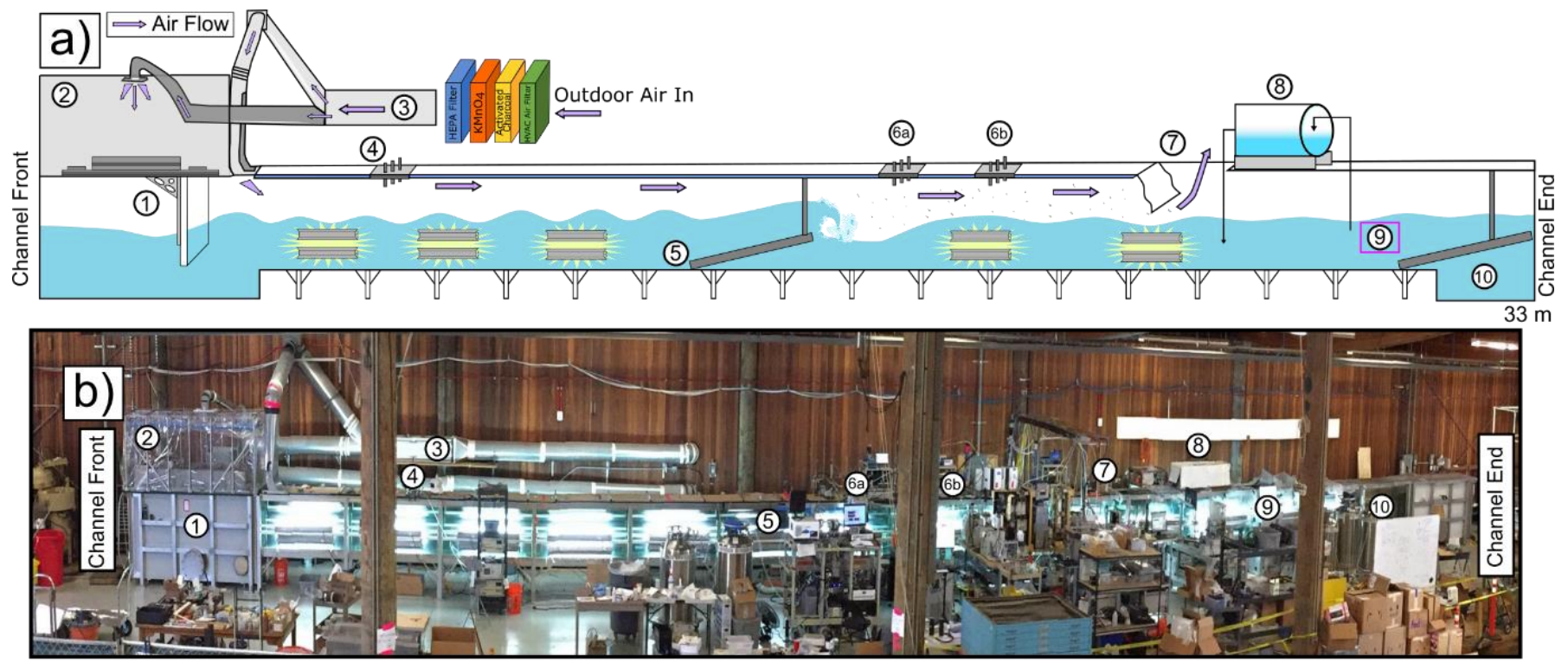

\begin{tabular}{|lc|}
\hline Wave Channel Location & Distance from Front $(\mathrm{m})$ \\
\hline (1) Reciprocating Paddle System & $0-2.6$ \\
\hline (2) PTFE Pressure Compensation Tent & $0-2.6$ \\
\hline (3) Air Handling Entrance Ports & $0,3.2$ \\
\hline (4) Upstream Sampling Port & 6 \\
\hline (5) Wave-Breaking Beach & $10.9-13.3$ \\
\hline (6) Headspace Sampling Ports & $16,17.5$ \\
\hline (7) Headspace outlet, PTFE Isolation Film & 20.6 \\
\hline (8) Isolated Sampling Vessel & 21.6 \\
\hline (9) Bulk Water Sampling Location & 28 \\
\hline (10) Wave-Dampening Beach & $29-33$ \\
\hline
\end{tabular}

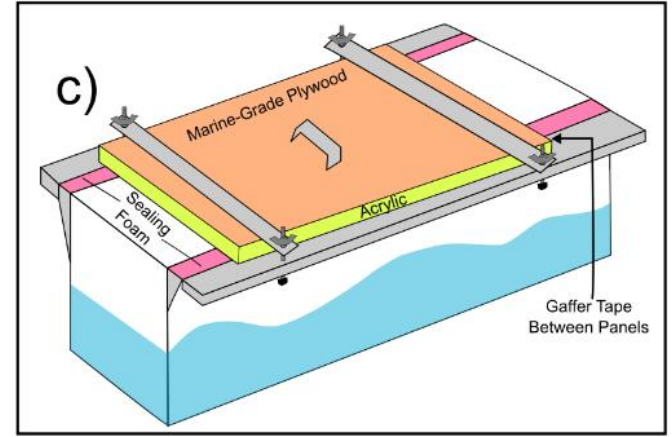

Figure 1. a) Schematic of the SIO Ocean-Atmosphere Interaction Facility (OAIF) wave Channel with key points labeled by number and described in the table, b) Photograph of the SIO OAIF channel with key points marked, c) Cross sectional view of wave channel lids which were used to seal the channel headspace. 


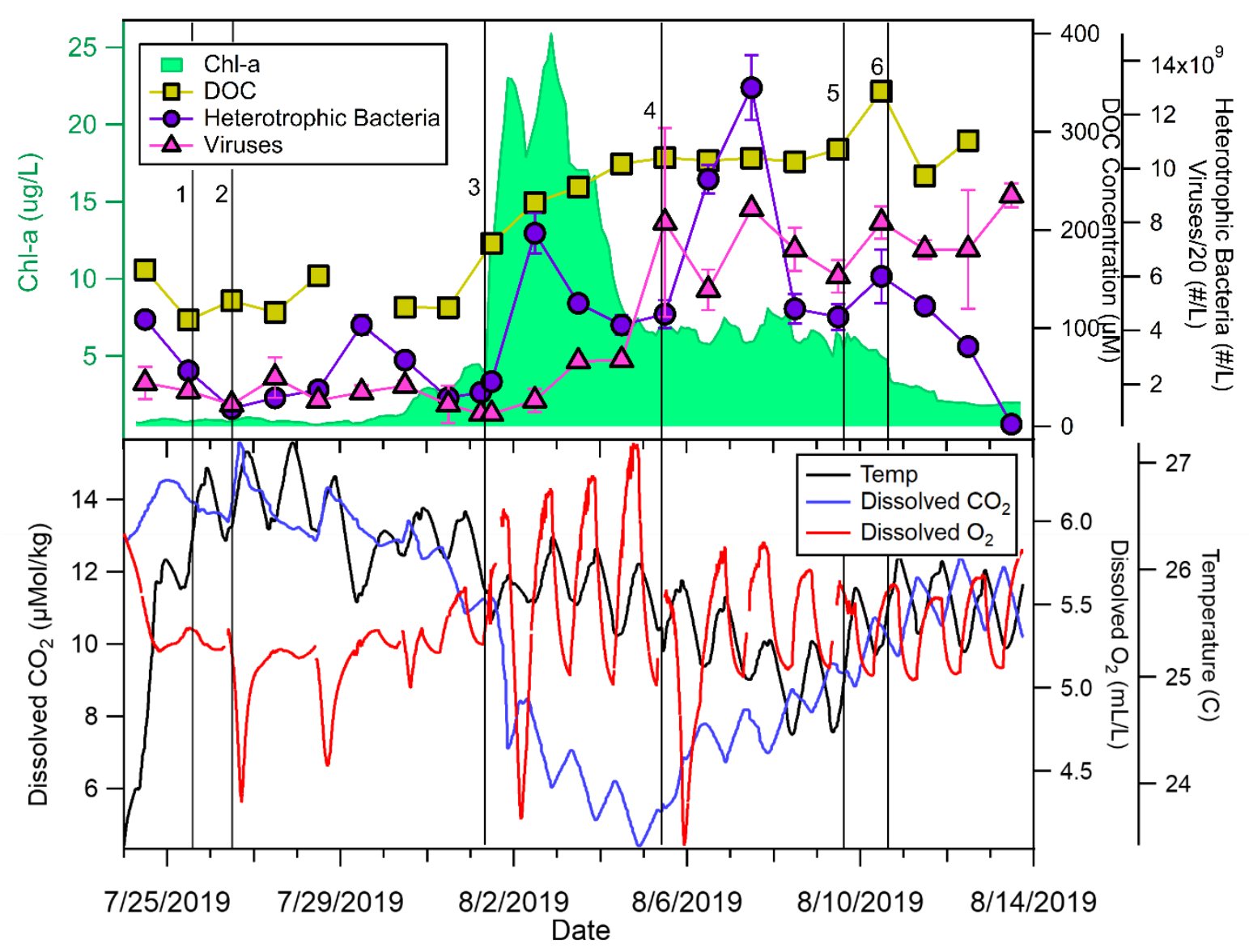

Figure 2. a) SeaSCAPE Bloom 3 chl-a, DOC, heterotrophic bacteria, and virus counts over the mesocosm duration. Numbered vertical lines indicate notable interventions in mesocosm. Lines 1 and 2 correspond to nutrient additions specified in Table 1. Line 3 corresponds to the addition to the wave channel of water from an outdoor tank in which a bloom was induced from the same source water. Line 4 corresponds to the scraping of wave channel walls to remove lightobstructive detritus. Lines 5 and 6 correspond to the addition of circulating pumps to resuspend 
cellular material that had settled on the wave channel bottom. b) Bloom 3 water temperature, 1445 dissolved $\mathrm{CO}_{2}$, and dissolved $\mathrm{O}_{2}$. 


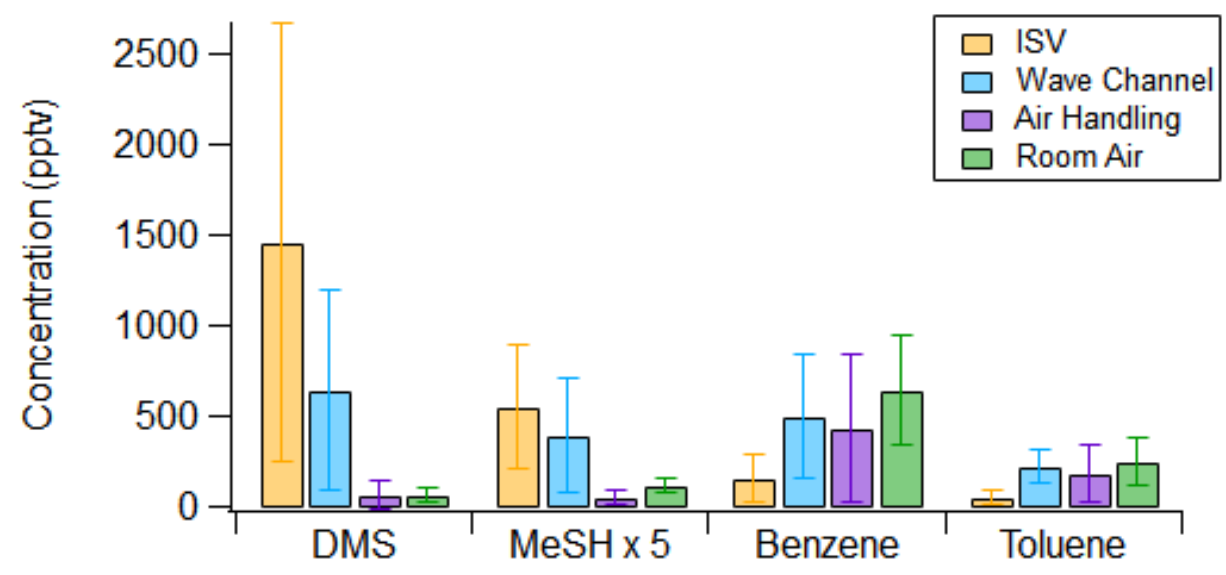

Figure 3. Histogram comparing daytime mixing ratios of DMS, MeSH, benzene, and toluene in the isolated sampling vessel (ISV), wave channel headspace downstream of wave-breaking, 1450 air handling system, and hydraulics laboratory room air. Bars show the averages over the entirety of Bloom 3, and error bars represent the $1 \sigma$ standard deviation over the daily average measurements. 


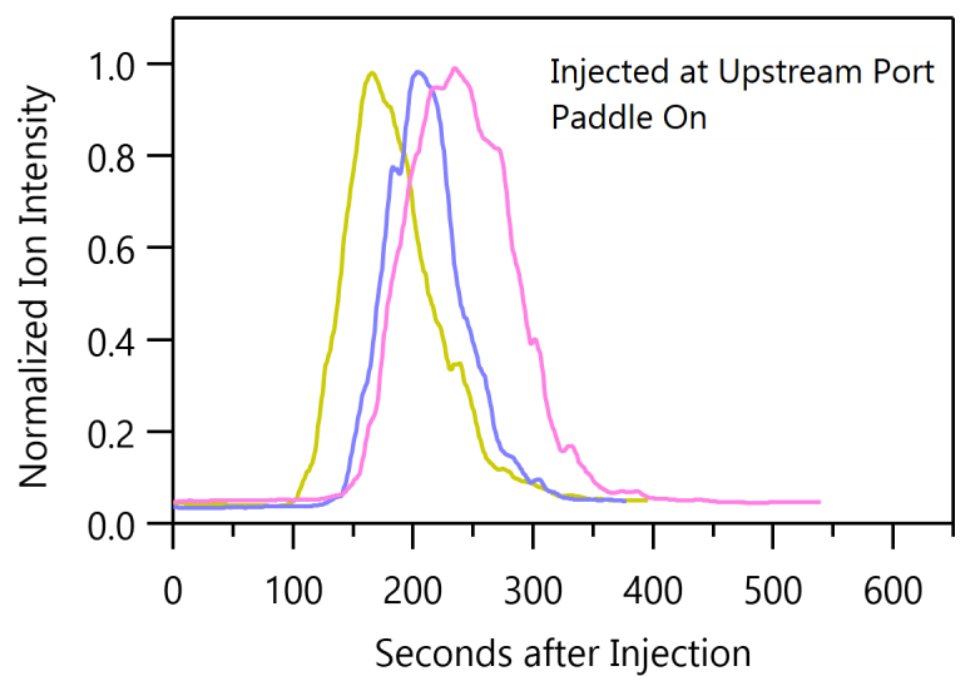

Figure 4. Replicate experiments of dimethyl sulfide (m/z 62) arrival time at the downstream sampling port measured by CI-TOFMS. Instrument signal was boxcar smoothed into 10 second bins. Sample injections were made sequentially on the same day. 


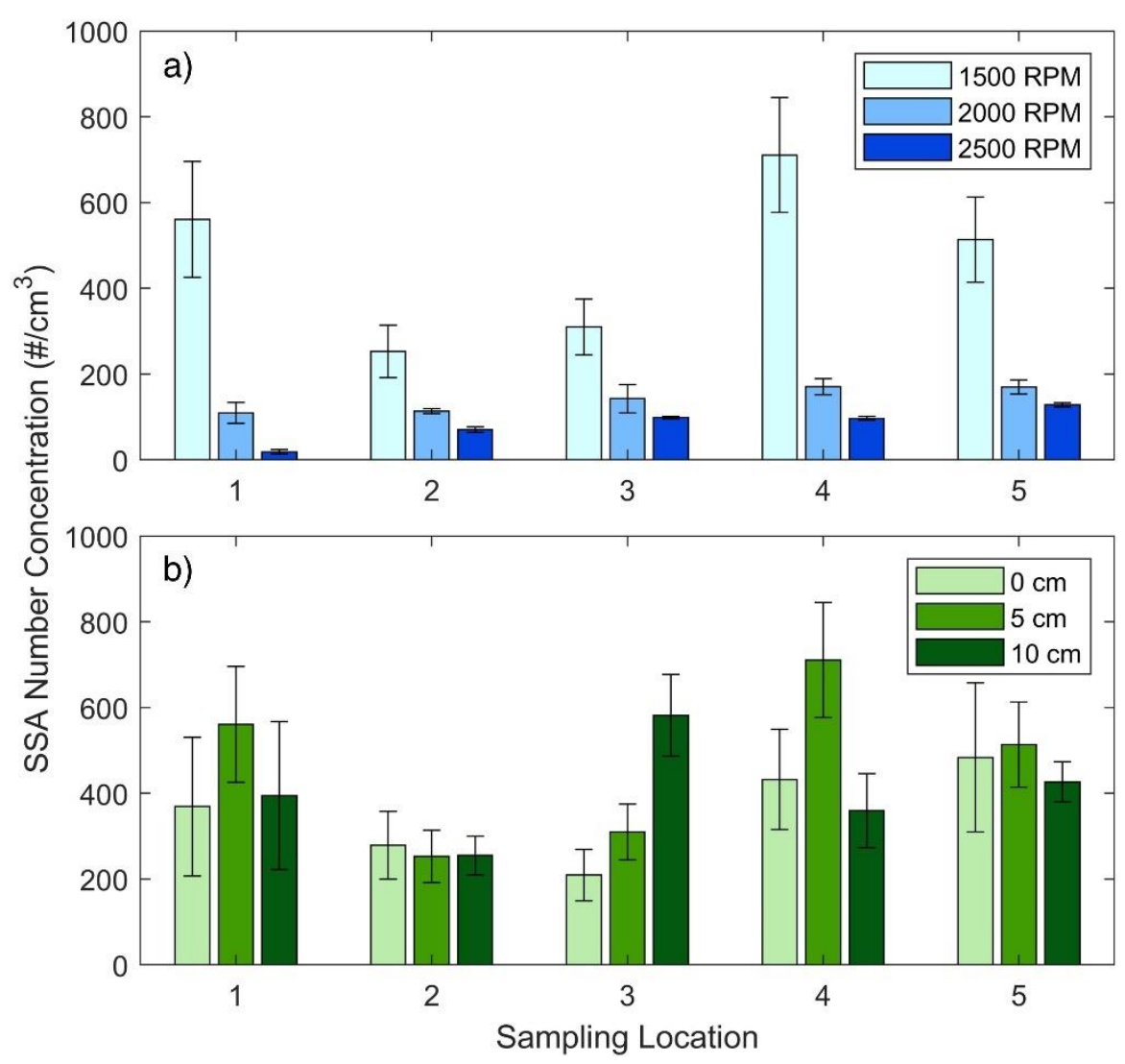

1460

Figure 5. a) SSA number concentration measured at 5 sampling locations with a $5 \mathrm{~cm}$ port depth, testing 3 different fan settings, which control the air velocity in the wave channel headspace. The lowest setting (1500 RPM) was determined to yield the highest SSA concentrations at all sampling locations. b) The SSA number concentrations at the different 1465 sampling locations with a fan speed of 1500 RPM, showing the effect of sampling port depth $(0 \mathrm{~cm}, 5 \mathrm{~cm}$, and $10 \mathrm{~cm}$ below the channel lids). There is no clear relationship between sampling port depth or location and number concentration, indicating heterogeneous particle concentrations in the channel headspace. The sampling port locations are evenly spaced and 
correspond to $0 \mathrm{~cm}, 60 \mathrm{~cm}, 120 \mathrm{~cm}, 180 \mathrm{~cm}$, and $240 \mathrm{~cm}$ from the downstream end of the 1470 beach. 

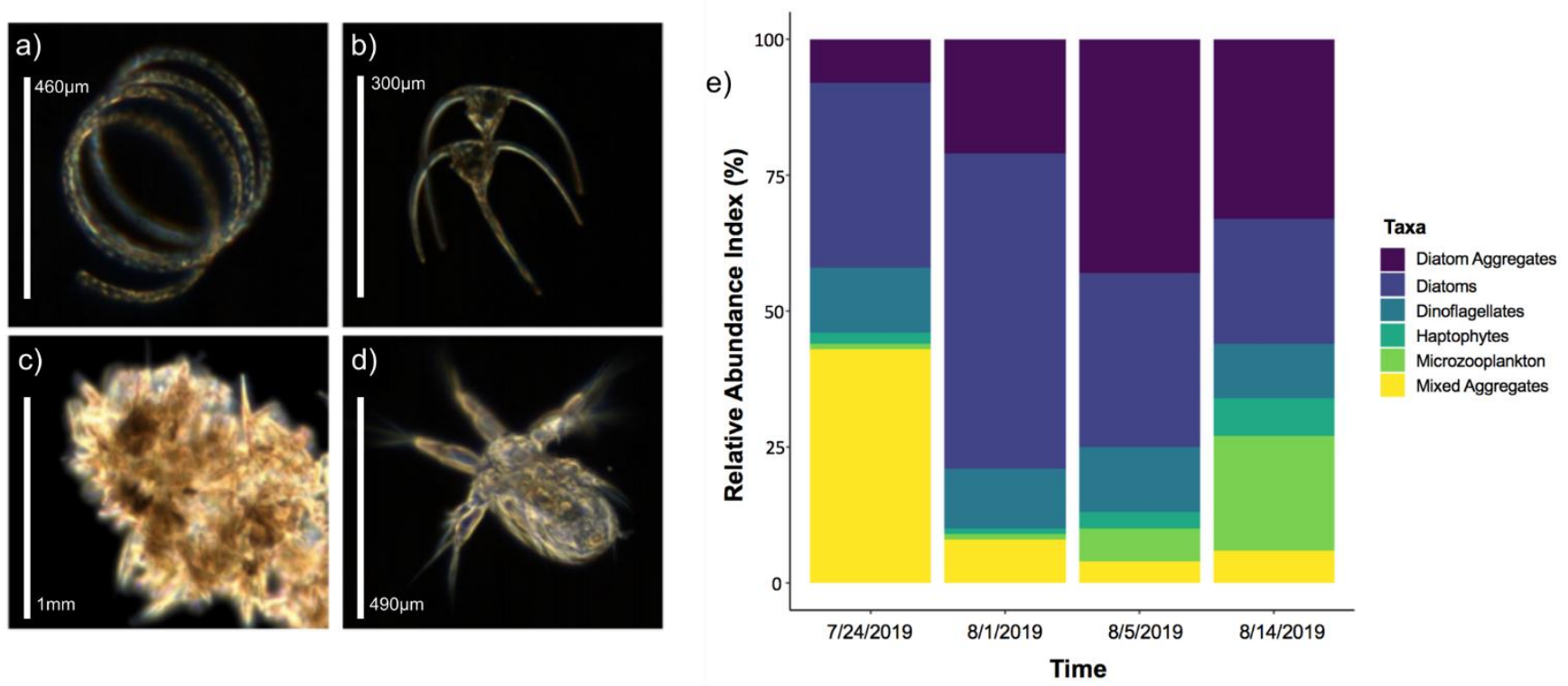

Figure 6. Micrographs of representative taxa across Bloom 3 showing a) diatoms; b) dinoflagellates; c) mixed aggregates (dominated by diatoms and haptophytes); d) nauplius 1475 (microzooplankton), e) Time series of relative speciation of phytoplankton taxa across SeaSCAPE. 
Post-Transportation Dissolved Organic Matter: Comparison to Pre-Transport

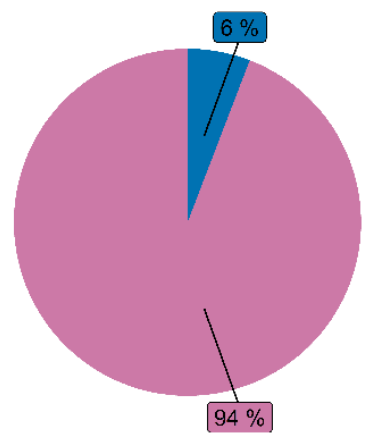

Bloom

Dissolved Organic Matter: Comparison to Pre-Bloom

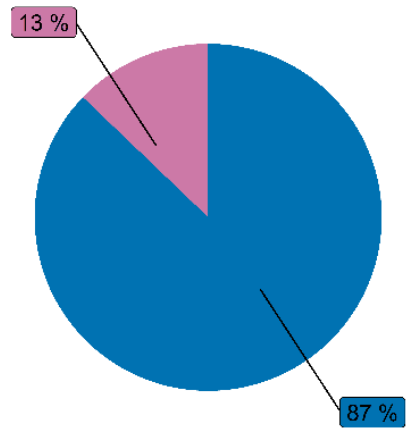

Previously Present

Significantly Enhanced

or Introduced
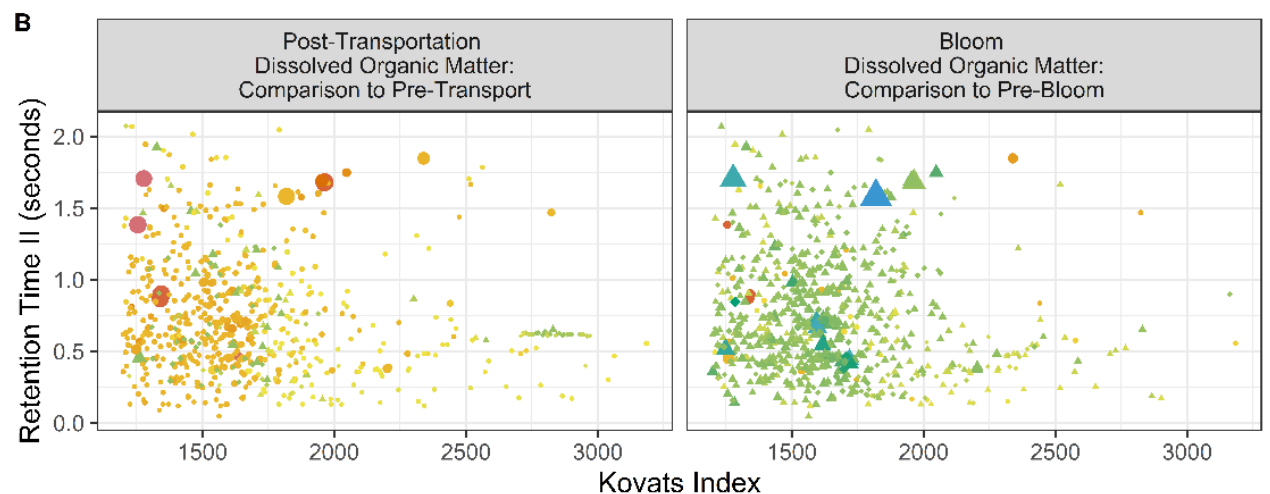

Compound Class

Normalized Signal

Signal Change

- Introduced

- Enhanced

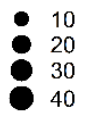

from Previous Sample

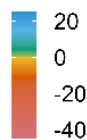

Figure 7. a) Composition of DOM (semi-quantified by internal standard normalized GCxGC

1480 ion signal intensity) after physical water transport from Scripps Pier (left) and after introduction of the concentrated bloom addition of 8/1 (right), segregated by change relative to prior sample, with pink indicating signal attributable to previously present compounds and blue attributable 
to species that are newly introduced or significantly (>15\%) enhanced in comparison to the prior signal. b) GCxGC spectra of DOM from Bloom 3, post-transportation from Scripps Pier

1485 into the wave channel (left) and post-bloom addition (right) samples illustrating the relative changes from pre-perturbation conditions. 


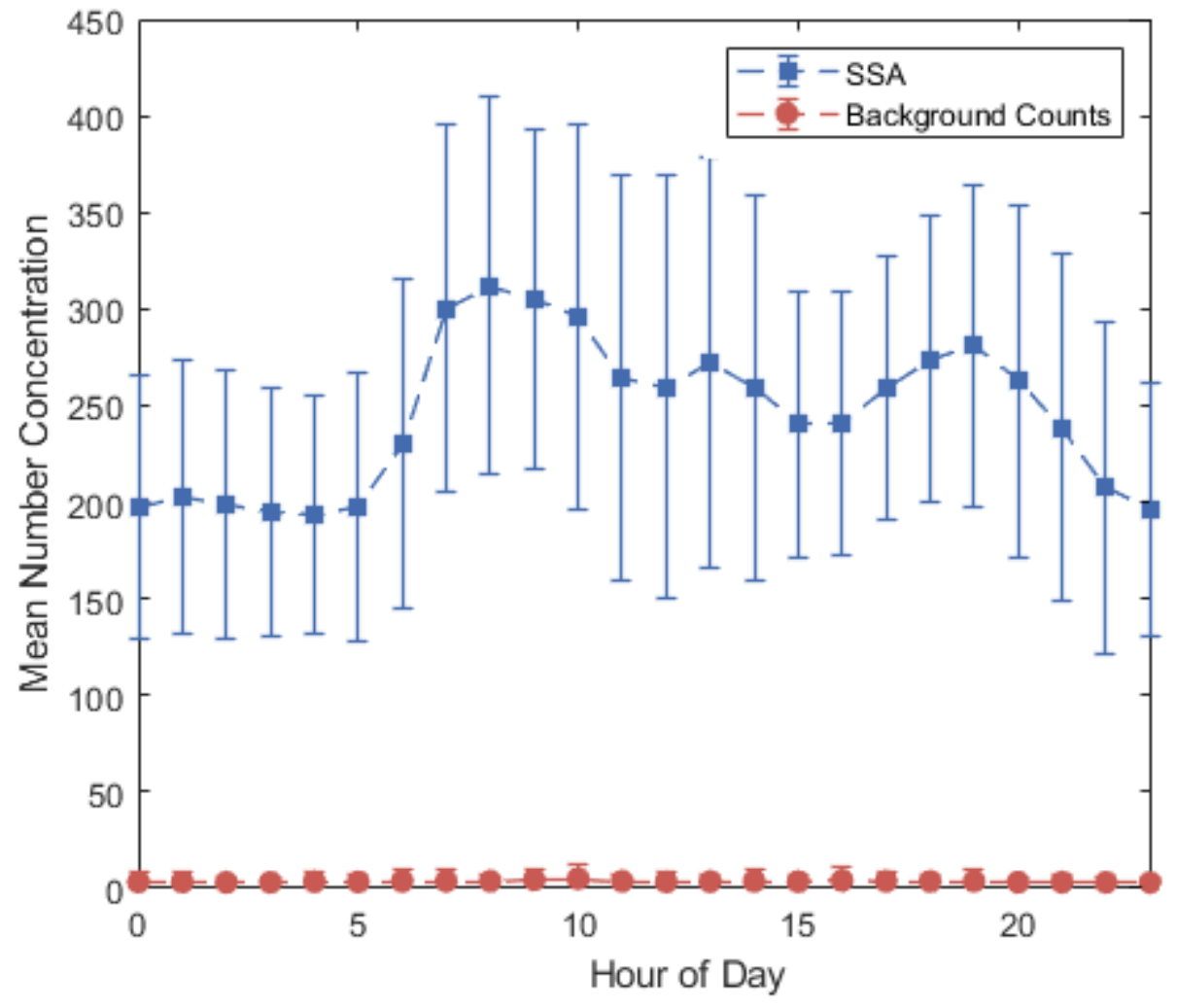

1490 Figure 8. Hourly average SSA number concentrations for all of Blooms 2 and 3, as measured by the APS and SMPS, demonstrating the variability in aerosol production, as well as the observed diurnal behavior. In general, particle concentrations tended to be higher and more variable during the daytime, but lower and more stable overnight. Background particle counts, as measured by the upstream CPC, are also shown. Times reflect local time (PST). 


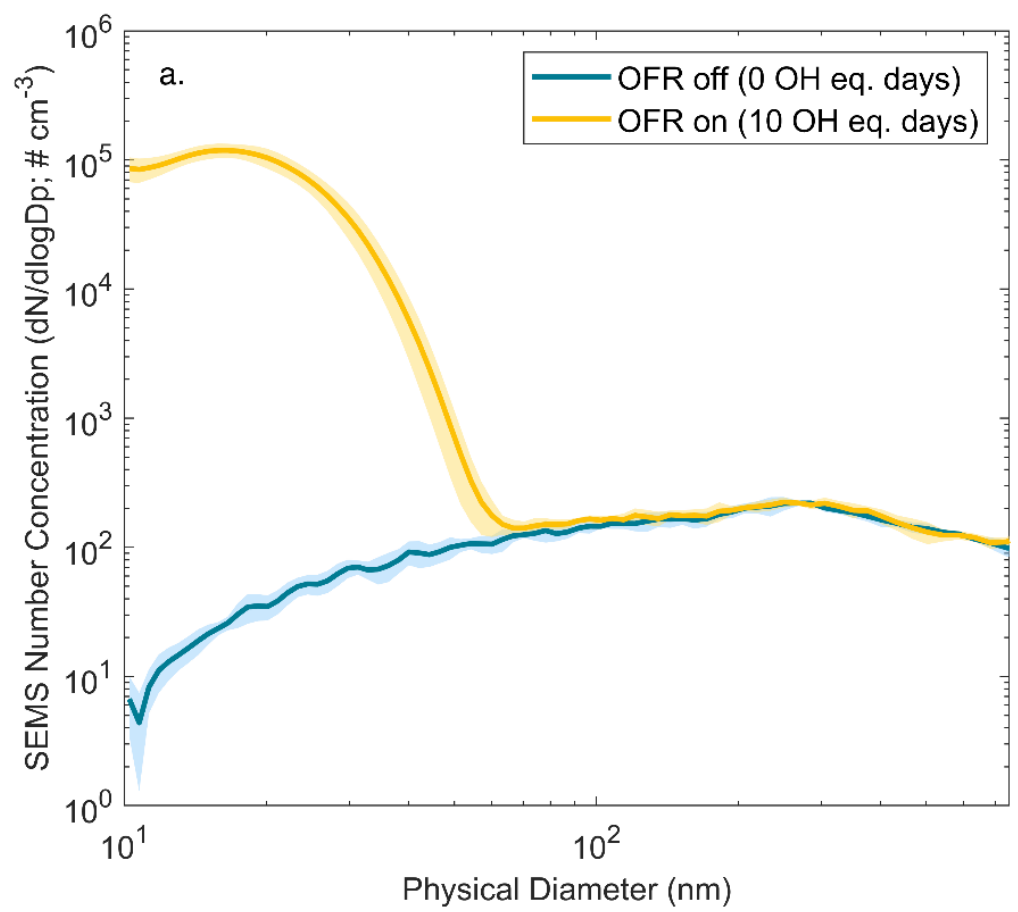

b. $0 \mathrm{OH}$ eq. days

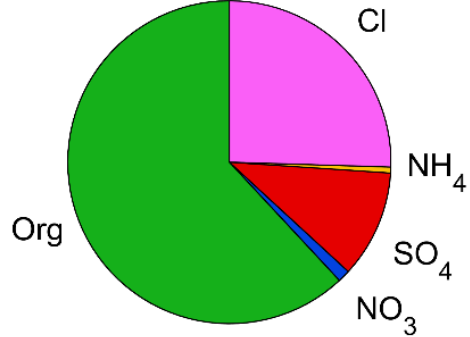

Aerosol Mass: $0.8 \mu \mathrm{g} \mathrm{m}^{-3}$

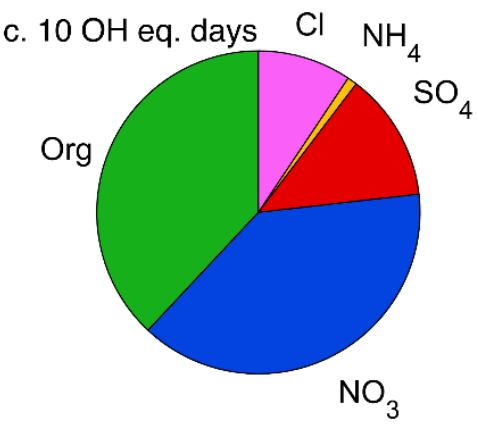

Aerosol Mass: $2.1 \mu^{-3} \mathrm{~m}^{-3}$

Figure 9. Representative aerosol size distribution from OFR1 (a), in which the complete mixture of gases and SSA from the wave channel headspace are oxidized in the OFR. Shading represents variability in the particle concentrations during the sampling period $( \pm 1 \sigma)$. The ultrafine mode at $<100 \mathrm{~nm}$, which is present only when the lamps are active, is evidence of new particle formation in the reactor. Median fractional bulk chemical composition of submicron non-refractory aerosol, as measured by the AMS, for (b) nascent/bypass SSA and (c) SSA aged $10 \mathrm{OH}$-equivalent days in the OFR. It is important to note that only a fraction of the total chloride is measured by the AMS. 

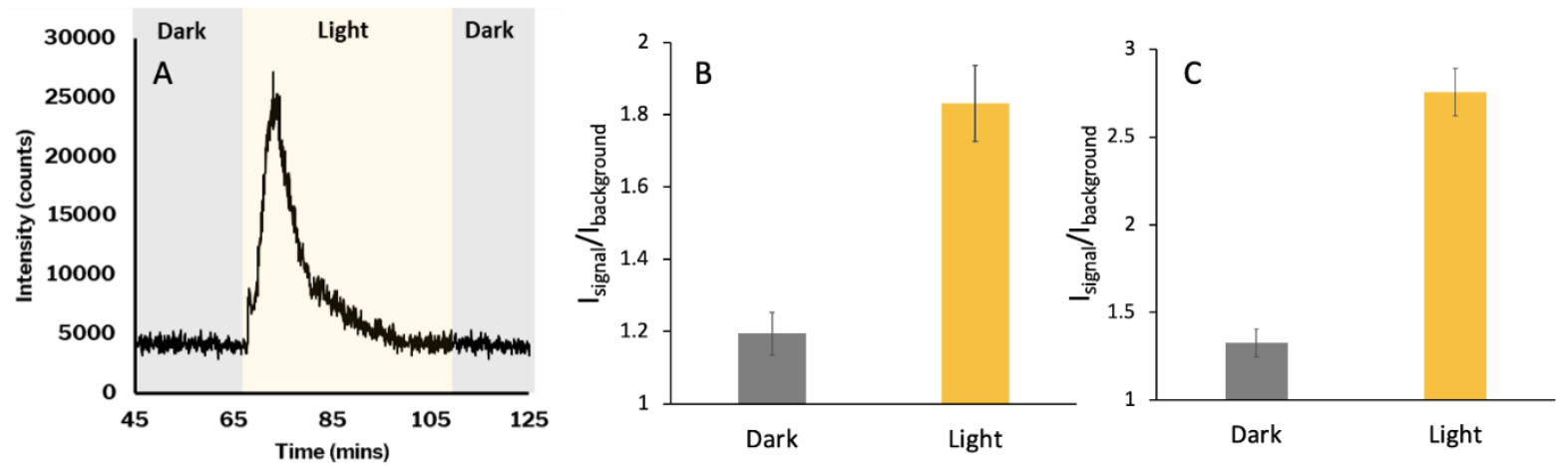

Figure 10. Data from gas-phase APCI high resolution mass spectrometry showing a) total ion current of summed volatile species found to be sensitive to irradiation, where gray indicates when the sample was kept dark and yellow when the sample was subjected to light; b) the signal enhancement of $\mathrm{C}_{6} \mathrm{H}_{6} \mathrm{O}$, likely phenol, upon irradiation, and c) the signal enhancement of $\mathrm{C}_{10} \mathrm{H}_{16} \mathrm{O}$, or beta-cyclocitral, upon irradiation. Error bars represent one standard deviation of the signal averaged over its highest peak. 


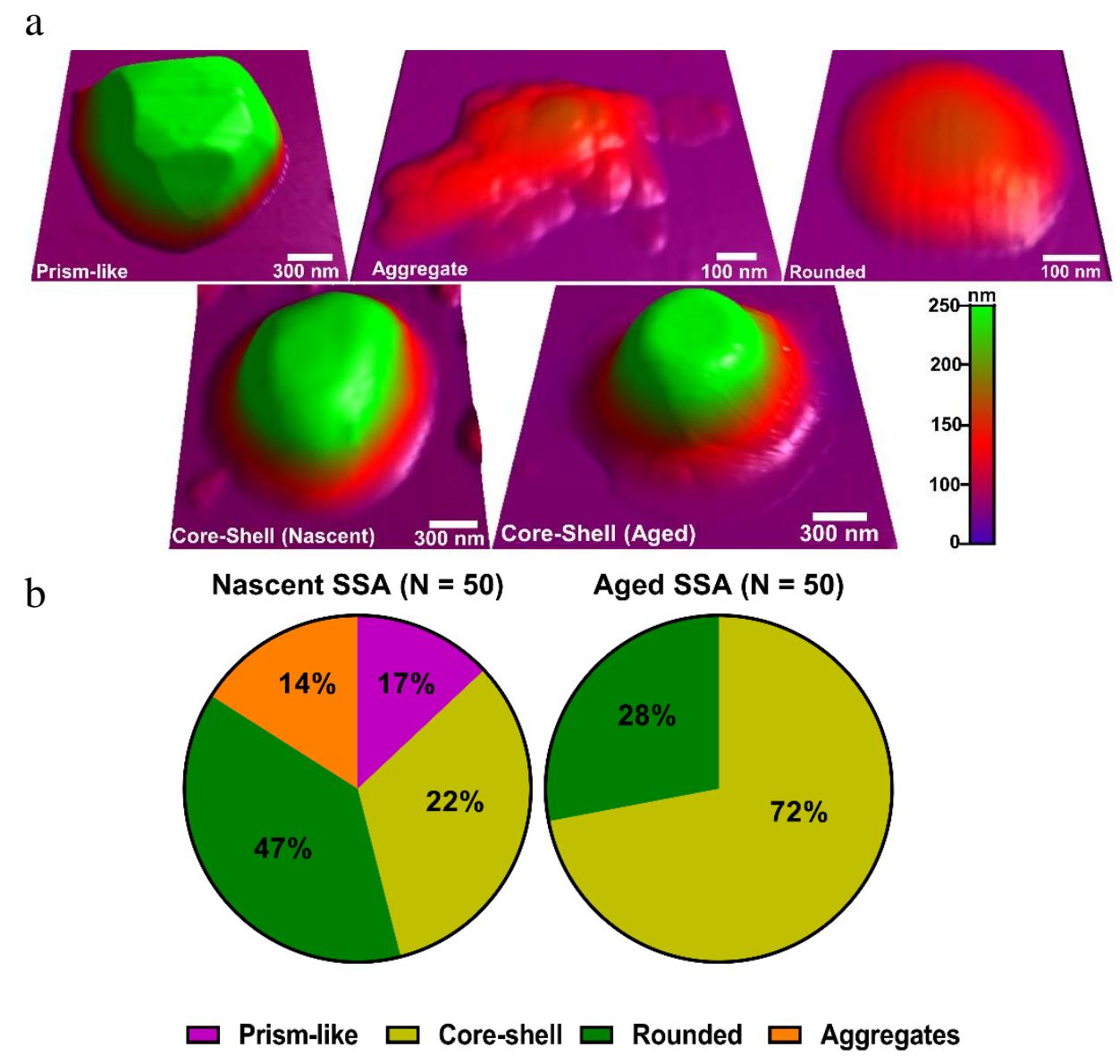

Figure 11. a) Representative AFM 3D-height images of individual SSA particles observed during the peak-bloom (Aug $3^{\text {rd }}$ ). Color scale shows height difference between the particles. b) Relative distribution of the morphologies in nascent and aged SSA samples. Prism-like, coreshell, rounded, and aggregates particles are represented by purple, yellow, green, and orange 1525 colors, respectively. 


\section{Table of Contents Graphic:}

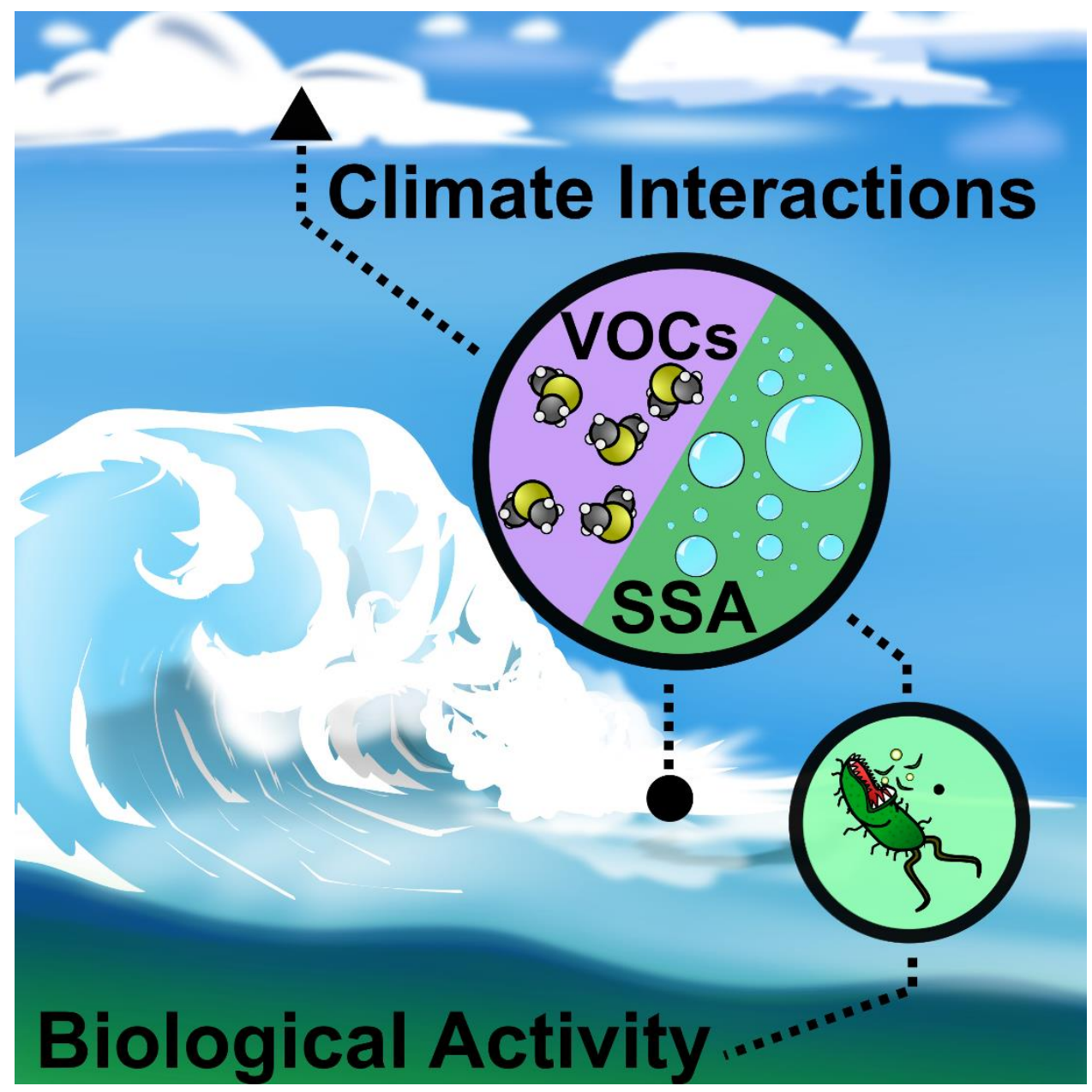

